\title{
Review of key factors controlling engineered nanoparticle transport in porous media
}

Mei Wang ${ }^{1,2}$, Bin $\mathrm{Gao}^{2 *}$, Deshan Tang ${ }^{1}$

1. College of Water Conservancy and Hydropower Engineering, Hohai University,

Nanjing 210098, PR China

2.Department of Agricultural and Biological Engineering, University of Florida, Gainesville, FL

32611, USA

* Corresponding author, phone: (352) 392-1864 ext. 285, Fax: (352) 392-4092, email:

bg55@ufl.edu

(C) 2016. This manuscript version is made available under the Elsevier user license http://www.elsevier.com/open-access/userlicense/1.0/ 


\begin{abstract}
Nanotechnology, an emerging technology, has witnessed rapid development in production and application. Engineered nanomaterials revolutionize the industry due to their unique structure and superior performance. The release of engineered nanoparticles (ENPs) into the environment, however, may pose risks to the environment and public health. To advance current understanding of environmental behaviors of ENPs, this work provides an introductory overview of ENP fate and transport in porous media. It systematically reviews the key factors controlling their fate and transport in porous media. It first provides a brief overview of common ENPs in the environment and their sources. The key factors that govern ENP transport in porous media are then categorized into three groups: 1) nature of ENPs affecting their transport in porous media, 2)nature of porous media affecting ENP transport, and 3) nature of flow affecting ENP transport in porous media. In each group, findings in recent literature on the specific governing factors of ENP transport in porous media are discussed in details.Finally, this work concludes with remarks on the importance of ENP transport in porous media and directions for future research.
\end{abstract}

Keywords: nanoparticles; environmental impact; fate and transport; retention; deposition; mobilization 


\section{Introduction}

Engineered nanomaterials (ENMs), composed of basic elements with one or more external dimensions below $100 \mathrm{~nm}$, are amongthe most promising manufactured materials of high homogeneity[1]. Characterized by unique magnetic, thermal, electronic, optical, and photoactive properties [2], ENMsare being used extensively in industrial and consumer applications, such as electronics, energy, environment, pharmaceuticals, biomedicine, cosmetics, textiles, paints, and nutrition[3-5]. Currently, ENMs have been estimated to possess great market potential on a global scale[6-8]. It is predicted by National ScienceFoundation that nanotechnology would drive global economic output of roughly $\$ 3,000$ billion and absorb 6million practitioners engaged in nanomaterial-related products in 2020 [9]. With the increasing production and use of various ENMs, growing concern has been raised over their unavoidable release into the environment, which may pose potential risks to the ecosystems and public health[10, 11].

In recent years, much attention has been devoted to assess the impacts of engineered nanoparticles (ENPs) in the environment. ENPs can enterthe air, water, and soil environmental during the processes of manufacturing, transportation, consumption or disposal[3, 12].Hence, it is veryeasy for living beings in close contact with ENPs through dermal contact,inhalation, and ingestion. A number of studies have demonstrated that ENPs of various types, such as nanosizedmetals and metal oxides[13], are toxic to both aquatic and terrestrial organismsat certain concentrations. Hanna et al. reported that ENPs have significant adverse effects on seed plants, such as decreasingseed germination and leaf formation, as well as increasing frequency of 
lateral root developmental disturbances[14]. Hazardous effects of ENPs on the aquatic life have been also observed by considerable research [15]. Furthermore, human-health risks induced by exposure to ENPs, such as genetic disease, lung and pleural fibrosis andcarcinogenesis, and systemic immune disorders, have been revealed[16-19]. Given that ENPs entering the environment may pose risks to the ecosystems and public health in the foreseeable future, an understanding of their fate and transport and fate is crucial for monitoring and controlling theirenvironmental behaviors, and thus reducing their exposures.

Research on environmental fate and transport of ENPs is rapidly entering a phase of significant scientific progress.Massive amounts of publicationsinthis area can be found throughsearchingScopus and Web of Science databases. In particular, experimental and modeling studies on the fate and transport of ENPs in porous media occupy a considerable percentage of the search results. These investigations showed that the transport of ENPs is influenced by a variety of factors, e.g., size, shape, structure and surface characteristics of ENPs and media [11, 20-23], ENP concentration[22, 24], as well as flow conditions likepH, ionic strength (IS)and flow velocity[25-27]; theydraw different conclusions under various scenarios. This expanding body of literature aboutthe key factors controlling the transport of ENPs in porous media, however, has not yet been systematically reviewed.

It is probably unrealistic to write a comprehensive review article to cover all the aspects of the environmental fate and transport ENPs at this point of time, partially because there are too many published papers on this topic in the literature. Recently, several good review articles with 
focuses on specific topics of different processes or behaviors of ENPs inporous media and the environment have been published[12, 28-30]. Nevertheless, the key factors that govern the interactions between ENPs and surrounding media within porous media received relatively less attention in the previous reviews. In particular, some important factors (e.g., nanoparticle concentration, nanoparticle shape, grain surface roughness or medium type) were overlooked and the combined effects of multiple conditions on ENP transport in porous media were not systematically discussed in the previous reviews.

The objective of this work was to provide an introductory overview of the key factors controlling the retention and transport of ENPs in porous media under various conditions. To avoid overlapping and maintain the simplicity, it only covers the aspects of the key processes and main mechanisms that govern the interactions between ENPs and surrounding media under various environmental conditions. Soil, as plant food foundation and natural barrier to pollution infiltration, plays a significant role in the environment. Knowledge regarding the key factors of ENP transport in porous media is helpful to understand the behaviors of ENPs in soil and groundwater systems, thus minimizing their hazardous impacts.

\section{ENPs in the environment}

In this review, ENMs specifically refer to intentionally produced materials formed by nanoscale particles that are homogeneous in size, shape, and structure[1, 31]. Common ENMs can generally be divided intofollowing four types[10, 32]: (i) metal-based ones, including 
zero-valent metals, metal oxides, and metal salts; (ii) carbon-based ones, including fullerene, carbon nanotube(CNT), graphene and its derivatives (e.g., graphene oxide $(\mathrm{GO})$ and reduced graphene oxide (rGO)), black carbon,carbon nanofiber, etc.; (iii) semiconductornanocrystals (quantum dots), such as zinc sulfide (ZnS) and cadmium sulfide (CdS); and (iv) nanostructure polymers and composites, such as zinc coordination polymers[33], conducting-polymer coated GO [34],semiconducting-ferroelectric polymer nanocomposites[35], etc. ENMs tend to have excellent properties, making themselves promising for commercialuse. The ENM-related production has already boomed at an exponentially increasing speed, which inevitablyincreasesthe chance of ENM release.

Products containing ENMsmainlyenter the environment in threeforms(waste gas; waste water; and industrial residues) and may release ENPs into air, water, and soil systems. The fate and transport of the ENPs in the environment are complicated and involve many processes (Fig. 1). Exhausts from vehicles, industrial manufacturing, and waste incinerationcontribute torising concentrations ENPs in the atmosphere. These nanoparticles cangather by condensation and crystallizationthrough fog or precipitationand will finally subsideonto groundorwater surfaces; however, most ENPs in the surface water bodies are from wastewater discharges. Even though the majority of particles can be removed by processing in wastewater treatment plants, the capacity is still not enough for preventing a range of ENPs released into surface water[36]. After being released with treated or untreated effluents, these ENPs may remain suspended in water or constantly aggregate and settle down to the bottom sludge. During these processes, they 
are easily absorbed and accumulated by aquatic organisms. Similarly, soils may receive ENPs from sewage discharges. In addition, landfills, remediation of contaminated soil and water, and nanoscale chemical fertilizer applied foragriculturalpurposesmay also introduce ENPs to the soil systems[37]. Soil systemsare distinguished by the presence of a heterogeneous mixture of gas, liquid, and soil phases, the interfaces between them, and the presence of organicmatter and microbial communities[38]. Without a doubt, the transport of ENPs in soils, one of the most common porous media, is vastly complicated. ENPs in the soils may be involved inmany environmental processes. They can beretained at different interfaces, permeate throughsoil vadose zone into groundwater, enter into water bodies through base flow, or be absorbed directly by soil organisms[39].In particular, the ingestion, transformation, and translocation of ENPs by the microorganisms are among the most important natural process in soil and groundwater systems $[12,40]$. This important topic has been reported in several previous studies including two recent review articles $[12,40]$. To avoid overlapping and maintain the simplicity, this worktherefore onlyfocus on the key process of ENP transport in porous media.

Several types of ENPs have been released into the environment from various sources (Table 1). Kelly et al. [37] estimated the release of ENMs at global scale and identifiedtencommon ENPs (i.e.,zinc oxide $(\mathrm{ZnO})$, carbon nanotube $(\mathrm{CNT})$, silica $\left(\mathrm{SiO}_{2}\right)$, titanium dioxide $\left(\mathrm{TiO}_{2}\right)$, alumina $\left(\mathrm{Al}_{2} \mathrm{O}_{3}\right)$, iron $(\mathrm{Fe})$ and iron oxides, nanoclay, cerium oxide $\left(\mathrm{CeO}_{2}\right)$, silver $(\mathrm{Ag})$, and copper $(\mathrm{Cu})$ and copper oxides)in the environment. They suggested that, apart from the majority of ENPs ending up in landfill, most are emitted to soilsor water;release toair can be ignored from 
the perspective of quantity[37].Furthermore, ENPs are easilysorbedontosoil particles because of their extremely large surface area-to-mass ratio and then accumulate in the food chains [41].Because there are emerging evidences of the potential toxic effects of some of the ENPs, such as carbon-based [42-45] and metal-basedones [38, 46], bioaccumulation of ENPs in soils may pose great risks to the ecosystems and public health.

Because of this serious situation, a goodunderstanding of the transport behaviors of these ENPs in porous media isextremely important. More than 1000 documents can be found in the Web of Science database, using a topic search of "transport", "nanoparticle(s) or nanomaterial(s)", and "porous media or sand or soil".Fig.2 shows the specific numbers of research articles of different ENPs on this topic since 2000. There are no relevant records prior to 2000, which from another side reveals the research is anemerging topic. Based on the database, Fe-based nanoparticles attract most attention in the last fifteen years, followed by $\mathrm{TiO}_{2}, \mathrm{Ag}$, and carbon-based (especially CNTs and fullerenes) nanoparticles. To summarize the recent developments in this research and elucidate the fundamental mechanisms, this review arranges key factors controlling the fate and transport of ENPs in porous media around these listedin Fig. 2, but not limited to them.

\section{Nature and concentration ofENPs affect their transport in porous media}

The properties of ENPs play a decisive role in controlling theirenvironmental behaviors.

This section is to elucidate the effects of ENP characteristics pertinent to themselves on transport 
in porous media, byfocusing on thesize and surface properties. Besides these two aspects, shape and input concentration have also been put forward to account forENP transport in porous media witha limited number of literatures.Because the values of hydrodynamic diameters of most ENPs fall inside the range of colloids, existing theories applicable to colloids (for instance, Derjaguin-Landau-Verwey-Overbeek (DLVO) theory and filtration theory) may be used to describethe transport of ENPs in porous media[47]. Special attention is needed, as ENPs may possess both colloidal properties and contaminant characteristicssimultaneously.

\subsection{Particle shape}

Particle shape is known to be an important property that strongly affects application and performance of particles [48]. To date, however, the amount of studieson how particle shape affects ENP transport in porous media is far from adequate[49, 50]. Furthermore, most of them focus on colloidal particles rather than narrowing down to ENPs explicitly [51, 52].

ENPs, especially carbon-based ones, often have various shapes such as layer, tube, sphere, wire, rod and fiber[50, 53]. Carbon is a unique element and is regarded as the backbone of life because it is basis of living matter on the earth. Fullerene $\left(\mathrm{C}_{60}\right)$, single-walled carbon nanotube (SWCNT), and multi-walled carbon nanotube (MWCNT) can all be derived from graphene (Fig. 3). Despite belonging to allotropes of carbon, these four ENPs have different transport behaviors in porous media. The differences of mobility of MWCNTs (tubular) and $\mathrm{C}_{60}$ (spherical) under similar environmental conditions have been investigated by Hedayati [54]. The author found that 
$\mathrm{C}_{60}$ displayed slightly higher mobility than MWCNTs in porous media when the IS was increased to $10.89 \mathrm{mM}$. An opposite trend was observed at higher IS (between 10.89 and $60 \mathrm{mM}$ ), as MWCNTs were much more mobile than $\mathrm{C}_{60}$., This phenomenon was ascribed to the formation of large aggregates of $\mathrm{C}_{60}$ at high IS, which promotesstraining or even sedimentation in porous media. Additionally, MWCNTs were also superior to $\mathrm{C}_{60}$ in mobility with the increase of input concentration when other conditions unchanged. These results indicated that particle shape plays an important role in controlling the fate and transport of ENPs in porous media, especially when coupled with other factors.

Not only do differences occur among allotropes of the same element, but also the transport of ENPs of the same type would be different in porous media if their shapes were not uniform. Several previous studies have demonstrated that the straining of SWCNTs in porous media may be strongly affected by their irregular shape and high aspect ratio; the longer SWCNTs have higher chances to be retained throughthe straining mechanism[55]. MWCNTs were observed to encounter a similar situation, as particles with higher aspect ratio have lower mobility in porous media[56].

Seymour et al.[49] examined the transport of spherical and rod-shape (stretched from the spherical ones) latex nanoparticles with aspect ratios of 1:1,2:1 and 4:1 in porous media. Spherical nanoparticles showed higher deposition rate than rod-shape nanoparticles under favorable conditions andtheir deposition rate increased with growing IS; while IS had no notable effects on the retentionof the rod-shape ones under the same conditions. These results are 
consistent with the findings from previous investigations carried out on colloid transport in porous media $[52,57]$. The authors[49]also found that rod-shape ENPs displayed an increase in deposition rate with time under unfavorable conditions, whereas spherical ones showed an opposite trend, further confirming the importance of particle shape to the transport of ENPs in porous media.

It is still not very clear why the particles with different shapes act differently in porous media under the same environmental conditions. It has been suggested that filter ripening is a possible mechanism for raised depositionrate of rod-shape ENPs as previously attached particles behave like collectors with physical roughness, rendering more particle retention. For spherical ENPs, however, the subsequent particles have no space to attach, as rapidly deposited particles fill the available attachment sites, and the deposition rate falls with time. Yet, the knowledge of the role of particle shape plays on the transport of ENPs in porous media is very limited and therefore needs further investigations.

\subsection{Particle size}

According to the DLVO theory and the colloid filtration theory, particle size should have strong influences on the transport of ENPs in porous media[58].In a column experiment on the transport of MWCNTs with different diameters, O'Carroll et al. [59] found that MWCNTs with smaller diameters show greater retention in sand porous media, which is consistent with the colloid filtration theory as well asfindings of several other experiments $[22,58,60]$. The colloid 
filtration theory indicates that decreasing particle size may lead to the increase of their collisions with porous media because of enhancedBrownian movement[59]. Wang et al. [58] also reported that silica ENPs with smaller size tended tohave a faster deposition rate and lower surface coverage than the larger ones at the same number concentration. However, considerable release of smaller ENPs from the secondary minima after injection of deionized water was observed compared to the limited release amount of larger ones. This is contrary to the DLVO prediction that more of the smaller, instead of larger, ENPsshould be retained in primary minimum rather than in secondary minima.Several other studies have also raised doubts about whether the DLVO theory is applicable to ENPs, particularly theextremely small sizes $(<10 \mathrm{~nm})$ ones [61, 62].

Conversely, anotherconclusion from previous studies on size effect on particle (particularly colloids) transport is that larger ones were less mobile [63-65]. Wang et al. [66]reported that MWCNT retention increased with increasing tube length in water-saturated quartz sand and the greatest deposition, composing mainly of long MWCNTs, has been found near the column inlet. Physical straining has been suggested to be a key factor for the retention of the long MWCNTs[66], probably because CNTs are a one-dimensional nanomaterial with a high aspect ratio [55]. Other studies have reported similar experimental phenomena, however, exclude the possibility of straining asa major contributing mechanism. May and Li [64] suggested that high deposition rate of large ENPs is mainly due to heterogeneity in the surface charge. Their results indicated that smaller particles are more sensitive to the physical and chemical surface heterogeneity than the larger ones, thus showing more obvious mobilization and 
reattachmentwhen ISis lowered. Pelley and Tufenkji[67] also observed an increase in attachment efficiency withincreasing sizeof latex ENPs.

An increase in transport distance with increasing particle size in porous media due to aggregationhas been also observed in previous studies [22, 68].Auffan et al.[69]argued that ENPs that have primary size smaller than $30 \mathrm{~nm}$ hardly exist. As a result,ENP transport in porous media is strongly dependent on the aggregate sizeinstead of the primary particle size[11, 38]. This result makes it difficult to determine the influence of primary size of ENPs, particularly small ones, on their transport in porous media. Additional attentions thus are needed to investigate the aggregation behaviors of small ENPs, particularly those below $30 \mathrm{~nm}$, in porous media.

One could easily argue that there are disagreements about the size effect on thetransportof ENPs in porous media in existing literatures. Some studies suggest that larger particles have demonstrate higher deposition, while others showthat higherdeposition is attributed to smaller nanoparticles; some studies even suggest that, under unfavorable conditions, the effect of particle size on ENP deposition in porous media could be negligible [70]. The discrepancies are probably because ENP transport in porous media is also affected by other factors and their combinations, such physical straining, surface charge heterogeneity, surface roughness, hydrodynamic interactions, etc. Particle size affects ENP transport mainly through two mechanisms, Brownian diffusion and straining, which are also influenced by other factors such as flow velocity and grain size. Furthermore, the use of conflicting measurement unitsforparticle concentrations, i.e., 
mass concentration $(\mathrm{mg} / \mathrm{L})$ and particle number concentration (particles/mL) [58], may lead to faulty comparisons even under the same conditions. There are several reasons for poor DLVO prediction, such asvariety in the scope of application[58] and the inaccurate hypothesis that both collectors and particles are spherical[67]. All things considered, making a definite assessment on the effect of particle size on ENP transport in porous media may not be realistic at this point.

\subsection{Particle concentration}

Exposure of ENPs at high concentrationsand the accompanying toxic risk for various organisms isof great concern[71-75]. To date, several studies have investigated theconcentration-dependent behaviors of ENPs in porous media and some drawn inconsistent conclusions because of variations in experimental conditions. For example, one study found that an increase in particle-collector attachment efficiency and increasing input concentration of carboxymethyl cellulose (CMC)-modified nano-zero-valent iron (NZVI)induces a rapid increase in aggregation size with time as a result of increased attachment efficiency and collision chance[24]. Using polymer-modified NZVI, however, Phenrat et al.[70] showed that the attachment isextremely smallat low concentration $(30 \mathrm{mg} / \mathrm{L})$ and that even at high concentration ( 1 to $6 \mathrm{~g} / \mathrm{L}$ ), the attachment efficiency is stillvery low and thus insensitive to changes of input concentration. Particle-collector interactions and quick formation of the stabled sized agglomerates accounted for the two experimental phenomena at low and high concentrations, respectively. 
Most of the existing studies, however, showed a relatively consistent result that higher mobility occurred under higher input concentration under unfavorable conditions, clearly different from those drawn by above two studies. In an experiment with GO transport in sand columns [22], higher particle recovery rates in the effluents at higher input concentration have been reported for coarse and mediumsand, with the value at $25 \mathrm{mg} / \mathrm{L}$ nearly double that at 5 $\mathrm{mg} / \mathrm{L}$. This result is in agreement with the findings of previous studies on MWCNT [56, 76], nanosized $\mathrm{Al}_{2} \mathrm{O}_{3}[77,78]$, and $\mathrm{Ag}$ nanoparticles[79]. Wang et al. [58] examined the effect of silica ENP concentration on their retention and transport in porous media using particle number concentration, while all the other studiesin this section used mass concentration. Nonetheless, their results also showed steady-state effluent concentrations increase with input concentrations, similar to results from the majority of available literature[22, 27, 56, 76-79]. The enhanced mobility of ENPs with increased input concentration has been to the blocking effect that attachment sites on the grain surface are occupied more quickly at a higher concentration[22, 56].

It is worth noting that a pronounced increase in themobility of nano- $\mathrm{TiO}_{2}$ has beenunexpectedly observed under favorable conditions as the particle input concentration increases[27], where both DLVO theory and straining mechanism would not provide a reasonableexplanation. Other mechanisms (e.g.,blocking and aggregate breakup) thus could be the possible candidates causing the surprising phenomenon [27]. 


\subsection{Particle surface properties}

Surfaceproperties of ENPs, such as surface charge and hydrophobicity,govern theirinteractions with interfaces of the surrounding media. Because of the strong Van der Waals attractions, pristine ENPs have a strong tendency to aggregate, which may limit theirapplications. For the optimal uses, several modification methods including chemical oxidation and surfactant coatinghave been applied to improve thestability ENPs in aqueous solutions.

The use of surfactants, as a kind of hydrophilic organic materials, is one of the primary means to stabilize ENPs (Fig. 4). Surfactants are widely present in aquatic environments[80] and have shown strong influences on facilitating the transport of ENPs in subsurface environment[25, 47, 70, 81-83]. The presence of surfactants has also been found to reduce the aggregation of various ENPs including nanosized $\mathrm{TiO}_{2}[25,84,85]$, MWCNTs [76], GO [86], and Ag [79].Previous studies have explored the effects of different types of surfactants on ENP transport in porous media. Lu et al.[76] compared the effects of three different surfactants (i.e., sodium dodecylbenzenesulfonate (SDBS), octyl phenol ethoxylate (TX-100) and cetylpyridinium chloride (CPC), representing anionic, nonionic, and cationic surfactants, respectively) on MWCNT transport in quartz sand (negatively charged)columns. The surfactants played different levels of mobility, promoting MWCNTs in theorder of TX-100 $<\mathrm{SDBS}<\mathrm{CPC}$, which contradictsthe prediction of the DLVO theory that electrostatic interactions would make SDBS much more effective than CPC.It was suspected that surface charge heterogeneity caused by metal oxides/hydroxides (positively charged) on sand surface could be the main reason for this 
opposite trend [21, 87].In a follow-up study with columns packed with soils, Lu et al.[88]found that the mobility of the surfactant-modified CNTs followed an order of SDBS-CNT $>$ TX-100-CNT >CPC-CNT, consistent with the prediction of the DLVO theory. In comparison with their transport in quartz sand columns[76], surfactant-modified CNT transport in soils was relatively inhibited, showing shorter transport distance and entire retention, reflecting the importance of porous medium properties on ENP transport that will be discussed later.

Liu et al. [89] used two different surfactants (SDBS and cetyltrimethylammonium bromide (CTAB), negatively and positively charged, respectively) to modifygraphene surface and found that both surfactant type and concentration played significant rolesin controlling graphene transport in porous media. Their results indicated that, at low surfactant concentration, SDBS-modified graphene is much more mobile than CTAB-modified one, which has limited mobility in the media. At high surfactant concentration, however, CTABmodification dramatically enhances the mobilityof graphene; while the influence of SDBS is weakened. The same surfactants, however, have different effects on the transport of hydroxyapatite nanoparticles in porous media [90]. Although the two surfactants canstabilizethe ENPs through surface modification, they fail to enhance ENP mobility in the porous media under a certain range of surfactant concentrations.

In addition to surfactants, natural organic matters (NOMs) are also effective in stabilizing ENPs and enhancing their mobility in porous media[91]. NOMs are composed of multiple 
organic compounds, mainly two groups: humic substances and non-humic substances. Fulvic acid and humic acid are representatives of humic substances. Dissolved NOMs are easily absorbed on ENP surface and thus change their surface properties[92]. Because humic substances contain abundant carboxylic (-COOH) and phenolic(-OH) functional groups, they can exist as negatively charged poly-electrolytes[93].ENPs coated by humic substances often displaynegatively charged features, enabling themselves stable and mobile in porous media. For instance, Suwannee River humic acid (SRHA) has been demonstrated to reduce the attachment efficiency of several types of ENPs in porous media under various experimental conditions[23, 68]. This has been attributed to the combined mechanisms of electrostatic and steric repulsions[67]. Similarly, Mudunkotuwa et al.[94] reported that organicacids increase the mobility of nanosized $\mathrm{Cu}$ and $\mathrm{CuO}$ in porous media. It has also been reported that, under typical environmental concentrations, humicacids are sufficient to stabilize ENPs, such as nanosized $\mathrm{TiO}_{2}[81]$.

Oxidization is another surface modification method thatintroduces surface charges to ENPs. Tian et al. [95]compared three modification methods, i.e., oxidization, surfactant coating, and humic acid coating,on SWCNT transport in porous media and reported that surface oxidation is as effective as the other two methods in mobilizing the nanoparticle, particularly under water-saturated conditions. Similarly, GO obtained through oxidize graphene also shows relatively high mobility in porous media under various conditions $[22,96]$. 
The DLVO theory shows limitations in describing the fate and transport of surface-modified ENPs in porous media for most of the cases[47, 76]. There are several possible reasons for the failure of the theory. First, the default shapes of both particles and collectors in DLVO theory arespherical or flat, but in practical situations, ENPs and collector surfaces are usually irregular[67]. Second, the influence of surface modifier on DLVO interactionsis only included in IS calculations, which is not enough because surface properties and size of both particles and collectors are affected by the presence of surfactants or organic matters[76, 94]. Third, the presence of surface modifiers may contribute some non-DLVO interactions, such as steric interactions[76, 97]. Extended or modified DLVO theories have been developed and additional investigations are still needed to improve the theory for ENPs [98, 99].

\section{Nature of porous media affects ENP transport}

Porous media such as soils are very important to the fate and transport of ENPs in the environment. ENPs in subsurface may interact with multiple interfaces (i.e., solid-water, air-water, and air-water-solid interfaces) within the soils and be retained by the interfaces or break through soil to reach groundwater and drinking water aquifers [12]. Packed and undisturbed column experiments are often used to examine the transport behaviors of ENPs and have demonstrated the properties of porous media, such as medium type, surface property, grain size, and moisture content,substantially affect ENP transport. 


\subsection{Medium type}

The mobility of ENPs can be quite different in porous media of different types[100]. Glass beads, sand, and grabbed soils are common packing materials for column experiments and ENPs behavior different in them. For instance, the transport of the same ENPs in glass bead columns is often higher than that in sand column [23, 101, 102]. Wang et al. [101] compared the transport of nanoscale fullerene aggregates $\left(\mathrm{nC}_{60}\right)$ in columns packed with glass beads and quartz sand under similar experimental conditions and found thatmore $\mathrm{nC}_{60}$ was retained in the sand $(77 \%)$ than in glass beads ( $8 \%-49 \%)$. In another study of the transport of surface-modified iron nanoparticles, attachment efficiency values of $0.01,0.21$ and 0.18 were obtained for glass beads, unbaked sand, and baked and, respectively, confirming that ENPs are more mobile in glass beads than in sand[102].

Mobility of ENPs in soils, however, may be lower than intheother two media. Fang et al.[82] collected 14types of surface soils in China, and found that MWCNTs prefer to retain in soil columns with higher clay content rather those with higher sand content. They suggested that porous mediawith higher clay content have moresmall pores to retain the ENPs through physical straining; while higher sand content tends to create more big pores and shadow zones. Similar results of the effects of clay content of soils on the transport of colloidal and nanosized particles in porous media have been reported in several previous studies [88, 100, 103-105].Yang et al.[100] observed a decline of ENP mobility when sand was replaced by clay-rich soil in packed columns. Porosity and pore interconnectivity of columns packed with sand and grabbed soils are 
often different even when the two classes of media have asimilar range of grain size. In comparison to sand columns, the contributions of smaller pore sizes and larger surface area in soil columns increaseboth electrostatic interactions and physical straining and thus reduce the mobility of ENPs in the media[11].

In the literature, most of the laboratory studies on ENP transport in porous media used columns packed with sand or glass beads. Only few experiments usedreal soils[106, 107].It has been suggested that quartz sand and glass beads may not be good modelsfor studyingthe transport of ENPs in real soils [106]. Natural soilstypically possessunique mineralogical composition, which havethe potential to enhance the availability of favorable attachment sites or generate colloids or organic matter to facilitate transport.In another aspect, as mentioned above,clay content of the soils has the potential to create small pores to reduceENP mobility. The overall effect of natural soils, promoting or inhibiting ENP transport, is complicated and depends on otherphysiochemicalcharacteristics of the particles, media (collectors), and flow. Nevertheless, findings from columns packedartificial porous media, particularly quartz sand, have provided much useful information and valuable insight and advanced current understanding of the fate and transport of ENPs in porous media.

\subsection{Medium surface properties}

Previous studies have demonstratedthat surface properties of porous mediastronglyinfluence their interaction with ENPs and thus the transport of ENPs. Tian et al.[47]have reported the 
differences in Ag nanoparticle deposition and release in sand with different surface properties. They used organic-free (baked)sand and organic-metal-free (baked and acid washed ) sand and found that the retention of Ag nanoparticles in organic-free sand was higher. This indicatesthat the metal impurities (mainly metal oxyhydroxides) on medium surface, even at trace level, can strongly affect the transport of ENPs in porous media. In a follow-up study, Tian et al.[21] compared the transport of CNTs in columns packed with acid-cleaned, baked, and natural sand, and found that CNTs aremuch more mobile in acid-clean sand (i.e., free of metal oxyhydroxides) than in others.Further, when quartz sand surface was artificially covered with iron oxide, the mobility of $\mathrm{TiO}_{2}$ nanoparticles in the porous media was also reduced because of strong attractive electrostatic forces between ENPs and iron oxide on the sand surface [108].

Surfactants and NOMs are ubiquitous in the subsurface environment and thus may interact with porous media to alter their surface properties. When grain surfaces are coated by surfactants or NOMs, it may alter their transport of ENPs. For example,Lu et al.[88] and Liu et al. [89] have demonstrated that the adsorption of surfactant on sand grain surfaces strongly affects the retention and transport of CNTs and graphene in porous media, respectively. Chen et al.[109]modifiedglass bead surfaces with CPC and trimethylchlorosilane (THCS), a hydrophobic organosilicon compound. They found that $\mathrm{CPC}$ coating dramatically increases retention of $\mathrm{nC}_{60}$, while $\mathrm{nC} 60$ transport is not sensitive to the THCS-coating in comparison with the uncoated glass beads. 
Surface roughness of the medium can also affect ENP transport in porous media, particularly under unfavorable conditions, because higher roughness of the grain surface may weaken the repulsive interactions between the grain and particles, resulting in greater retention[110, 111]. In unsaturated porous media, reducing surface roughness may reduce the surface friction forces and lead to fewer particles been retained through capillary retention [112, $113]$.

\subsection{Grain size}

ENP transport is explicitly dependent on the grain size of porous media[38]. Several studies have pointedout that larger grain sizes lead to less deposition of ENPs in porous media $[76,114$, 115]. This is mainly because the surface area and the available attachment sites for ENPs decrease when the grain size increases $[114,115]$. In addition, finer grains may create smaller pores in porous media to increase the possibilityof physical straining mechanism[79, 116]. A recent study hasshown that increasing the grain size of quartz sand from $0.3-0.6 \mathrm{~mm}$ to $0.8-1.2$ $\mathrm{mm}$ causes the retention ofNZVI in porous media decreasing[116]. Similar effect of grain size on ENP transport in porous media has been observed for several carbon nanomaterials, including $\mathrm{C}_{60}[61]$, SWCNT $[20,95]$, MWCNT [56, 117], and GO [22]. It has been reported that decreases in soil grain size may also promote the release of clay particles from the soils that may clog soil pores to reduce the mobility of ENPs[88]. Because of their good filtration ability to 
colloids and nanoparticles, fine sand is considered as an alternative, low-cost filter for contaminant removal[22].

Phenrat et al. [118], however, reported that smallergrain sizesmay inhibitNZVI agglomeration and deposition and thus,promote their mobility in porous media, which contradicts the prediction of the filtration theory. This abnormal phenomenon has been attributed to the changes of hydrodynamic forces thatsmaller collectors increase the average fluid shear force acting on deposited particles, promoting dis-agglomeration and detachment in porous media $[70,119,120]$. Because the transport of ENPs in porous media can be affected by various factors, it does not seem unreasonable that the similar range of grain size may show different influences under different situations.

\subsection{Moisture content}

The term "saturated soil" means all soil pores arefully filled with water. Under saturated conditions, the subsurface environment is a two-phase space where solid-water interfacial interactions and pore straining mainly control the transport processes of particles[121]. On the other hand, "unsaturated soil" means that theair phase exits in the soil pores (Fig. 5), which may introduce additional mechanisms of ENP retention and transport in porous media, such as air-water interfacial attachment and water-film straining[122]. Particles may also be retained at the solid-water-air triple sites with a certain probability under unsaturated conditions[113, 123, 124]. Because of these additional mechanisms, ENP transport in unsaturated porous media 
ismuch more complex than that in saturated media.Many previous studies have shown that the retention of ENPs in porous media tended to be more pronounced when the moisture content is lower. Liu et al. [125] demonstrated that recovery rates of GO in unsaturated sand columns are lower than that in saturated ones under similar experimental conditions. Zhang et al. [126]and Chen et al.[127] have reported similar trends of enhanced retention of $\mathrm{C}_{60}$ and $\mathrm{TiO}_{2}$ nanoparticles in unsaturated media, respectively.

Lower moisture content may not guarantee the higher retention of ENPs in porous media. Tian et al.[20] have shown that SDBS-dispersedSWCNTs are highly mobile in both saturated and unsaturated porous media and show retention only at an extremely low moisture content $(<0.1)$ conditions. They suggested that the high mobility of the ENPs in the unsaturated porous media can be attributed to the fact that the SDBS-dispersed SWCNTs did not attach to the air-water interfaces (repulsive interactions) or was retained in the water-films under the tested conditions (diameter of the CNTs is smaller than water film thickness). Similarly, Mekonen et al.[117]reported that MWCNTs are also insensitive to moisture perturbations in the investigated range of $16-100 \%$.In a study of the transport of $\mathrm{TiO}_{2}$ nanoparticle in porous media, Fang et al. [128] also found that reduction in water saturation has no effect on the retention of the ENPs and excluded the air-water interface attachment mechanisms due to the dominance of repulsive interactions between negatively charged air-water interaction and $\mathrm{TiO}_{2}$ nanoparticles. In another study on retention and transport of surface modified SWCNTs (i.e., oxidization, surfactant coating, and humic acid coating) in porous media, Tian et al. [95] pointed out that reductions in 
moisture content promote the retention of the SWCNTs in some of the media; however, only oxidized SWCNTs are retained in unsaturated porous media through attachment on air-water interfaces.

\section{Nature of flow affects ENP transport in porous media}

Both physical and chemical properties of flow can strongly affect the retention and transport of ENPs in porous media. The physical properties mainly refer to hydrodynamic conditions of flowin porous media including velocity and direction, which affect the advective and dispersive transport of the ENPs. The chemical properties mainly refer to solutionIS, ion valence, and $\mathrm{pH}$, which can alter the interactions between ENPs and surrounding environment.

\subsection{Flow velocity and direction}

Several studies have suggestedthat the mobility of ENPs in porous media is positively correlated with flow velocity, i.e. mobility increases with flow rate[79, 107, 115, 129]. This trend is also consistent with the prediction of the filtration theory[130]. When all the other conditions are the same, flow velocity controls the accessibility of ENPs to the favorable deposition sites in porous media [107]. As flow velocity decreases, the single collector contact efficiency would increase due to the prevalence of diffusion over advection, thereby increasing the retention and limiting the mobility $[107,131]$. Slow exchange between mobile zones and immobile zonesmay become important at relatively low flow rates; this is one of themajor mechanismsthat 
governretention and transport of colloids and nanoparticles in porous media[132]. Further, low velocity in combination with either smaller grain size (i.e., smaller pores) or lower moisture content exerts more effect on increasing ENP deposition onto grain surfaces[116, 117]. Under certain condition, however, the role of flow rate in ENP transport in porous media may not be so clear. Lower mobility at higher flow velocity has been reported for both fullerene and SWCNTs[133],yet the reason for this abnormal phenomenon is still unclear. Increasing flow rate is a way to remobilize the retained ENPs in porous media. The higher the flow rate is, the more easily the retained nanoparticles will detach from porous media under relatively considerable hydrodynamic force.

Flow direction may also affect the transport of ENPs in porous media. Change of flow direction can remobilize part of the previously retained ENPs, particularly for the one retained through pore straining[21]. No significant detachmentwould occur for the ENPs retained through surface deposition; instead, those retained at pore throats of porous media are much easier to release. This is because ENPs attached to porous medium surfaces resultfrom the joint effects of hydrodynamic force, gravity, and Van der Waals and electrostatic double layer forces, while deposition at pore throats is mainly through physical straining.

\subsection{Solution pH}

Solution $\mathrm{pH}$ can change the zeta potential of ENPs and affects their fate and transport in porous media. As the $\mathrm{pH}$ increases, zeta potential of ENPs may reduce gradually(Fig. 6). When 
$\mathrm{pH}$ is around the point of zero charge (PZC), where thesurface potentialis approximately zero, the ENPs are in extremely unstable state. The repulsive force between ENPs hardly exists, so it is easy for ENPs to aggregate and deposition results[134]. The PZC values are different among ENPs, such as uraniumoxides ( $\left.\mathrm{pH}_{\mathrm{PZC}} \sim 5\right)$, iron oxides $\left(\mathrm{pH}_{\mathrm{PZC}} \sim 8\right)$, zinc sulfides $\left(\mathrm{pH}_{\mathrm{PZC}} \sim 2\right)$, and aluminum oxides ( $\left.\mathrm{pH}_{\mathrm{PZC}} \sim 9\right)$ [135]. Different ENPs thus show different surface charges and stability in the solutionseven at the same $\mathrm{pH}[134]$. When solution $\mathrm{pH}$ is below the PZC, the ENP surfaces are positively charged; when $\mathrm{pH}$ is over the PZC, the surfaces are negatively charged. The greater the absolute difference between eluent $\mathrm{pH}$ and $\mathrm{PZC}$ (i.e., $\left|\mathrm{pH}_{\text {eluent }}-\mathrm{pH}_{\mathrm{PZC}}\right|$ ), the higher the repulsion between ENPs is and the more stable they are. It has been demonstrated that ENP transport in porous media is low when the solution $\mathrm{pH}$ is near the $\mathrm{PZC}$, promoting their aggregation [136]. When ENP aggregate size is larger than a threshold, pore straining and gravitation sedimentation may increase their deposition in porous media. Surfactants and NOMs are often used to disperseENPs and it has been reported that the presence of surfactants in solution promotes the transport of $\mathrm{TiO}_{2}$ nanoparticles in saturated porous media, regardless of changes of solution $\mathrm{pH}[25]$.

Solution $\mathrm{pH}$ can also alter the surface charges of the porous media to affect ENP transport. Where solution $\mathrm{pH}$ is over the PZC values of both ENPs and collectors, electrostatic double-layer repulsive forces are induced, which reduces the deposition of ENPs in the porous media. Natural soil surfaces are always heterogeneously charged, which is mainly induced by minerals including metal oxyhydroxides[21]. When solution $\mathrm{pH}$ is increased over the PZC of the 
metal oxyhydroxides, the surface charge heterogeneity of porous media may diminish. This could reduce the favorable attachment sites for negatively changed ENPs and their mobility would increase[21]. Several previous studies have demonstrated that increase of solution $\mathrm{pH}$ from 5-7 to 9-10 promotes of the transport of various types of ENPs in porous media under different experimental conditions[21, 26, 115, 137]. In a study performed in the pH range of 1-12 [135], the highest recovery $(100 \%)$ of $\mathrm{TiO}_{2}$ nanoparticles from sand columns wasat $\mathrm{pH} 1$ (both ENPs and media are positively charged) and 10 (both ENPs and media are negatively charged); whereas, the lowest recovery $(3 \%)$ occurred at $\mathrm{pH}$ 7. This result not onlyconfirms the importance of the solution $\mathrm{pH}$ on the transport of ENPs in porous media, but also indicates that solution $\mathrm{pH}$ affects ENP transport mainly through altering the surface potentials of both ENPs and porous media.

\subsection{Ionic strength}

A number of existing studies have shown that increase in solution IS enhances the retention of ENPs in porous media under unfavorable conditions [55, 115, 138]. Further, solution IS can also affect the critical coagulation concentrations (CCC)of ENPs and thus their stability in porous media[139]. High IS has a tendency to compress the electrostatic double layer of ENPs and thus reduce the repulsive forces to promote aggregation or deposition (Fig. 7). In a series of laboratory sand column experiments, Feriancikova et al.[140]have demonstrated that the retention of GO is positively correlated withIS in saturated porous media. The GO shows high 
mobility in the sand columns at low IS (e.g., $1 \mathrm{mM}$ of $\mathrm{NaCl}$ ) conditions; however, its retention increasesdramatically when ISis $100 \mathrm{mM}[140]$. It is suggested thatcompression of the electrostatic double layer at high IS may introduce a net attractive force for GO deposition in porous media, which is consistent with the findings of the IS effects on the transport of other carbon nanomaterials such $\operatorname{asC}_{60}$ and $\mathrm{MWCNTs}[23,141]$. Similar effects of ISare also observed for ENP transport in unsaturated porous media [125, 128]. The previously retained ENPs can be remobilized by decreasing solutionIS, if they are trapped in the secondary minimum[140, 142 , 143]. If the particle deposition is through primary minimum or transferred from secondary minimum to primary minimum, reduction of solution IS may also cause a small portion of re-entrainment of the retained ENPs, which has been observed for both $\mathrm{TiO}_{2}$ nanoparticles and CNTs $[23,122,144]$.

\subsection{Valence of cation}

The valence of cation or salt type also plays an important role in affecting the stability and transport of ENP in porous media. Multivalent cations such as $\mathrm{Ca}^{2+}$ and $\mathrm{Mg}^{2+}$ are believed to behave better than monovalent cations (e.g., $\mathrm{Na}^{+}$and $\mathrm{K}^{+}$) in inhibiting the mobility of ENPs in porous media $[60,145]$. For instance, three different background concentrations of $\mathrm{NaNO}_{3}$ and $\mathrm{Ca}\left(\mathrm{NO}_{3}\right)_{2}$ (i.e., 1,10 , and $50 \mathrm{mM}$ ) were used to study the transport of $\mathrm{Ag}$ nanoparticles in porous media [107] and the results showed $\mathrm{Ca}^{2+}$ are much more effectively than $\mathrm{Na}^{+}$in inhibiting particle transport even at concentration of $1 \mathrm{mM}$ [107].Similar results have been observed for 
$\mathrm{nC}_{60}$ transport in unsaturated porous media [109]. Under similar experimental conditions, $\mathrm{nC}_{60}$ was highly mobile when $\mathrm{NaCl}$ concentration was $0.2-6 \mathrm{mM}$, whereas a considerable amount of $\mathrm{nC}_{60}$ was retained when $\mathrm{CaCl}_{2}$ concentrationwas at $6 \mathrm{mM}[109]$.Divalent or multivalent cationsdisplay an advantage in destabilizingand retainingfunctionalized carbon nanoparticlesrapidly because of the bridging effect between the cations and the surface functional groups[139, 146]. Salt type may also affect the remobilization of previously retained ENPs in porous media during IS perturbations. Chowdhury et al.[142]found that the re-entrainment degrees of previously retained GO in porous media during IS reduction were different in different salts with an overall trend of $\mathrm{NaCl}>\mathrm{MgCl}_{2}>\mathrm{CaCl}_{2}$, under similar experimental conditions.

\section{Conclusions and future directions}

Because of their potential risks to the environment and public health, the fate and transport of ENPs in porous media have been studied intensively in the literature. Findings from previous investigation indicate that ENP transport in porous media is controlled by the combination of various factors related to the physical and chemical properties of the nanoparticle, medium, and flow. Although remarkable progress has been made toward gaining a better understanding of the fate and transport ENPs in porous media, additional investigations are still in critical need because of the complexity of the process. Examples of future research directions include: 1) Extension of the DLVO theory or development of a new theory to better predict the interaction 
forces between ENPs and ENPs or ENPs and porous media, especially for the ENPs with irregular shapes and porous media with surface heterogeneities; 2)Development of better and more accurate analytical instruments or methods to detect and monitor ENPs, particularly in environmental samples; 3) Laboratory experimental investigations on the transport behaviors of ENPs in natural porous media intact soil columns under environmentally relevant conditions; 4)

Field studies on the fate and transport of ENPs in the vadose zone and groundwater; and 5)Development of mathematical models to better predict the retention, transport, and mobilization of ENPs in natural soils.

\section{Acknowledgements}

This work was partially supported by the NSF (1213333), theChina Scholarship Council (CSC), and the Fundamental Research Funds for the Central Universities (2015B33714).

\section{List of abbreviations}

$\begin{array}{ll}\mathrm{Ag} & \text { Silver } \\ \mathrm{Al}_{2} \mathrm{O}_{3} & \text { Alumina } \\ \mathrm{C}_{60} & \text { Fullerene } \\ \mathrm{CCC} & \text { Critical Coagulation Concentrations } \\ \mathrm{CdS} & \text { Cadmium Sulfide } \\ \mathrm{CeO}_{2} & \text { Cerium Oxide } \\ \mathrm{CMC} & \text { Carboxymethyl Cellulose } \\ \mathrm{CNT} & \text { Carbon Nanotube } \\ \mathrm{CPC} & \text { Cetylpyridinium Chloride } \\ \mathrm{CTAB} & \text { Cetyltrimethylammonium Bromide } \\ \mathrm{Cu} & \text { Copper }\end{array}$


DLVO

ENM

ENP

$\mathrm{Fe}$

GO

IS

MWCNT

NOM

NZVI

PZC

rGO

SDBS

$\mathrm{SiO}_{2}$

SRHA

SWCNT

THCS

$\mathrm{TiO}_{2}$

TX-100

$\mathrm{ZnO}$

$\mathrm{ZnS}$
Derjaguin-Landau-Verwey-Overbeek

Engineered Nanomaterial

Engineered Nanoparticle

Iron

Graphene Oxide

Ionic Strength

Multi-walled Carbon Nanotube

Natural Organic Matter

Nano-Zero-Valent Iron

Point of Zero Charge

Reduced Graphene Oxide

Sodium Dodecylbenzenesulfonate

Silica

Suwannee River Humic Acid

Single-walled Carbon Nanotube

Trimethylchlorosilane

Titanium Dioxide

Octyl-Phenol-Ethoxylate

Zinc Oxide

Zinc Sulfide 


\section{References}

[1] V.L. Colvin, The potential environmental impact of engineered nanomaterials, Nat Biotechnol, 21 (2003) 1166-1170.

[2] A.R. Petosa, D.P. Jaisi, I.R. Quevedo, M. Elimelech, N. Tufenkji, Aggregation and Deposition of Engineered Nanomaterials in Aquatic Environments: Role of Physicochemical Interactions, Environmental science \& technology, 44 (2010) 6532-6549.

[3] F. Gottschalk, B. Nowack, The release of engineered nanomaterials to the environment, J Environ Monitor, 13 (2011) 1145-1155.

[4] F. Gottschalk, T. Sonderer, R.W. Scholz, B. Nowack, Modeled Environmental Concentrations of Engineered Nanomaterials (TiO2, ZnO, Ag, CNT, Fullerenes) for Different Regions, Environmental science \& technology, 43 (2009) 9216-9222.

[5] F. Piccinno, F. Gottschalk, S. Seeger, B. Nowack, Industrial production quantities and uses of ten engineered nanomaterials in Europe and the world, J Nanopart Res, 14 (2012) 1-11.

[6] S. Becker, Nanotechnology in the marketplace: how the nanotechnology industry views risk, Journal of Nanoparticle Research, 15 (2013).

[7] T. Walser, F. Gottschalk, Stochastic fate analysis of engineered nanoparticles in incineration plants, Journal of Cleaner Production, 80 (2014) 241-251.

[8] E.H. Jones, C. Su, Fate and transport of elemental copper $(\mathrm{Cu} 0)$ nanoparticles through saturated porous media in the presence of organic materials, Water research, 46 (2012) $2445-2456$. 
[9] M.C. Roco, The long view of nanotechnology development: the National Nanotechnology Initiative at 10 years, Journal of Nanoparticle Research, 13 (2011) 427-445.

[10] S.J. Klaine, P.J.J. Alvarez, G.E. Batley, T.F. Fernandes, R.D. Handy, D.Y. Lyon, S. Mahendra, M.J. McLaughlin, J.R. Lead, Nanomaterials in the environment: Behavior, fate, bioavailability, and effects, Environ Toxicol Chem, 27 (2008) 1825-1851.

[11] T.K. Darlington, A.M. Neigh, M.T. Spencer, O.T. Nguyen, S.J. Oldenburg, Nanoparticle Characteristics Affecting Environmental Fate and Transport through Soil, Environ Toxicol Chem, 28 (2009) 1191-1199.

[12] D. Lin, X. Tian, F. Wu, B. Xing, Fate and Transport of Engineered Nanomaterials in the Environment, Journal of Environment Quality, 39 (2010) 1896.

[13] K. Aschberger, C. Micheletti, B. Sokull-Kluttgen, F.M. Christensen, Analysis of currently available data for characterising the risk of engineered nanomaterials to the environment and human health--lessons learned from four case studies, Environment international, 37 (2011) 1143-1156.

[14] S.K. Hanna, R.J. Miller, H.S. Lenihan, Accumulation and Toxicity of Copper Oxide Engineered Nanoparticles in a Marine Mussel, Nanomaterials-Basel, 4 (2014) 535-547.

[15] R.J. Griffitt, J. Luo, J. Gao, J.-C. Bonzongo, D.S. Barber, Effects of particle composition and species on toxicity of metallic nanomaterials in aquatic organisms Environmental Toxicology and Chemistry Volume 27, Issue 9, Environ Toxicol Chem, 27 (2008) 1972-1978. 
[16] A.B. Boxall, K. Tiede, Q. Chaudhry, Engineered nanomaterials in soils and water: How do they behave and could they pose a risk to human health?, Nanomedicine-Uk, 2 (2007) 919-927.

[17] H. Cowie, Z. Magdolenova, M. Saunders, M. Drlickova, S.C. Carreira, B.H. Kenzaoi, L. Gombau, R. Guadagnini, Y. Lorenzo, L. Walker, L.M. Fjellsbo, A. Huk, A. Rinna, L. Tran, K. Volkovova, S. Boland, L. Juillerat-Jeanneret, F. Marano, A.R. Collins, M. Dusinska, Suitability of human and mammalian cells of different origin for the assessment of genotoxicity of metal and polymeric engineered nanoparticles, Nanotoxicology, 9 (2015) 57-65.

[18] D.Y. Lai, Approach to using mechanism-based structure activity relationship (SAR) analysis to assess human health hazard potential of nanomaterials, Food and chemical toxicology : an international journal published for the British Industrial Biological Research Association, (2015).

[19] E.A. Thompson, B.C. Sayers, E.E. Glista-Baker, K.A. Shipkowski, A.J. Taylor, J.C. Bonner, Innate Immune Responses to Nanoparticle Exposure in the Lung, Journal of environmental immunology and toxicology, 1 (2014) 150-156.

[20] Y. Tian, B. Gao, K.J. Ziegler, High mobility of SDBS-dispersed single-walled carbon nanotubes in saturated and unsaturated porous media, Journal of hazardous materials, 186 (2011) $1766-1772$. 
[21] Y. Tian, B. Gao, Y. Wang, V.L. Morales, R.M. Carpena, Q. Huang, L. Yang, Deposition and transport of functionalized carbon nanotubes in water-saturated sand columns, Journal of hazardous materials, 213-214 (2012) 265-272.

[22] Y.Y. Sun, B. Gao, S.A. Bradford, L. Wu, H. Chen, X.Q. Shi, J.C. Wu, Transport, retention, and size perturbation of graphene oxide in saturated porous media: Effects of input concentration and grain size, Water research, 68 (2015) 24-33.

[23] Y. Tian, B. Gao, L. Wu, R. Munoz-Carpena, Q. Huang, Effect of solution chemistry on multi-walled carbon nanotube deposition and mobilization in clean porous media, J Hazard Mater, 231 (2012) 79-87.

[24] T. Raychoudhury, N. Tufenkji, S. Ghoshal, Aggregation and deposition kinetics of carboxymethyl cellulose-modified zero-valent iron nanoparticles in porous media, Water research, 46 (2012) 1735-1744.

[25] I.G. Godinez, C.J. Darnault, Aggregation and transport of nano-TiO2 in saturated porous media: effects of $\mathrm{pH}$, surfactants and flow velocity, Water research, 45 (2011) 839-851.

[26] I. Chowdhury, S.L. Walker, Deposition mechanisms of TiO2 nanoparticles in a parallel plate system, Journal of colloid and interface science, 369 (2012) 16-22.

[27] I. Chowdhury, Y. Hong, R.J. Honda, S.L. Walker, Mechanisms of TiO2 nanoparticle transport in porous media: Role of solution chemistry, nanoparticle concentration, and flowrate, $\mathrm{J}$ Colloid Interf Sci, 360 (2011) 548-555. 
[28] C.M. Park, K.H. Chu, J. Heo, N. Her, M. Jang, A. Son, Y. Yoon, Environmental behavior of engineered nanomaterials in porous media: a review, Journal of hazardous materials, 309 (2016) 133-150.

[29] S.J. Yu, Y.G. Yin, J.F. Liu, Silver nanoparticles in the environment, Environ Sci-Proc Imp, 15 (2013) 78-92.

[30] G. Cornelis, K. Hund-Rinke, T. Kuhlbusch, N. Van den Brink, C. Nickel, Fate and Bioavailability of Engineered Nanoparticles in Soils: A Review, Crit Rev Env Sci Tec, 44 (2014) 2720-2764.

[31] E.S. Bernhardt, B.P. Colman, M.F. Hochella, B.J. Cardinale, R.M. Nisbet, C.J. Richardson, L. Yin, An Ecological Perspective on Nanomaterial Impacts in the Environment, Journal of Environment Quality, 39 (2010) 1954.

[32] M. Sajid, M. Ilyas, C. Basheer, M. Tariq, M. Daud, N. Baig, F. Shehzad, Impact of nanoparticles on human and environment: review of toxicity factors, exposures, control strategies, and future prospects, Environmental science and pollution research international, 22 (2015) 4122-4143.

[33] F. Molaei, F. Bigdeli, A. Morsali, S.W. Joo, G. Bruno, H.A. Rudbari, Synthesis and characterization of different zinc(II) oxide nano-structures from two new zinc(II)-Quinoxaline coordination polymers, J Mol Struct, 1095 (2015) 8-14. 
[34] S.C. Ray, S.K. Bhunia, A. Saha, N.R. Jana, Graphene oxide (GO)/reduced-GO and their composite with conducting polymer nanostructure thin films for non-volatile memory device, Microelectron Eng, 146 (2015) 48-52.

[35] S.H. Sung, B.W. Boudouris, Systematic Control of the Nanostructure of Semiconducting-Ferroelectric Polymer Composites in Thin Film Memory Devices, Acs Macro Lett, 4 (2015) 293-297.

[36] A. Weir, P. Westerhoff, L. Fabricius, K. Hristovski, N. von Goetz, Titanium dioxide nanoparticles in food and personal care products, Environmental science \& technology, 46 (2012) $2242-2250$.

[37] A.A. Keller, S. McFerran, A. Lazareva, S. Suh, Global life cycle releases of engineered nanomaterials, Journal of Nanoparticle Research, 15 (2013).

[38] K.L. Garner, A.A. Keller, Emerging patterns for engineered nanomaterials in the environment: a review of fate and toxicity studies, Journal of Nanoparticle Research, 16 (2014).

[39] D. Lin, Environmental behavior and toxicity of engineered nanomaterials, Csb, 54 (2009) 3590 .

[40] G.V. Lowry, E.M. Hotze, E.S. Bernhardt, D.D. Dionysiou, J.A. Pedersen, M.R. Wiesner, B.S. Xing, Environmental Occurrences, Behavior, Fate, and Ecological Effects of Nanomaterials: An Introduction to the Special Series, Journal of environmental quality, 39 (2010) $1867-1874$. 
[41] G. Oberdorster, E. Oberdorster, J. Oberdorster, Nanotoxicology: An emerging discipline evolving from studies of ultrafine particles, Environ Health Persp, 113 (2005) 823-839.

[42] E.J. Petersen, L. Zhang, N.T. Mattison, D.M. O'Carroll, A.J. Whelton, N. Uddin, T. Nguyen, Q. Huang, T.B. Henry, R.D. Holbrook, K.L. Chen, Potential release pathways, environmental fate, and ecological risks of carbon nanotubes, Environmental science \& technology, 45 (2011) 9837-9856.

[43] M. Uo, T. Akasaka, F. Watari, Y. Sato, K. Tohji, Toxicity evaluations of various carbon nanomaterials, Dent Mater J, 30 (2011) 245-263.

[44] C.M. Goodwin, G.G. Lewis, A. Fiorella, M.D. Ellison, R. Kohn, Synthesis and toxicity testing of cysteine-functionalized single-walled carbon nanotubes with Caenorhabditis elegans, Rsc Adv, 4 (2014) 5893-5900.

[45] A. Simon, S.X. Maletz, H. Hollert, A. Schaffer, H.M. Maes, Effects of multiwalled carbon nanotubes and triclocarban on several eukaryotic cell lines: elucidating cytotoxicity, endocrine disruption, and reactive oxygen species generation, Nanoscale Res Lett, 9 (2014).

[46] P.S. Tourinho, C.A.M. van Gestel, S. Lofts, C. Svendsen, A.M.V.M. Soares, S. Loureiro, Metal-based nanoparticles in soil: Fate, behavior, and effects on soil invertebrates, Environ Toxicol Chem, 31 (2012) 1679-1692.

[47] Y.A. Tian, B. Gao, C. Silvera-Batista, K.J. Ziegler, Transport of engineered nanoparticles in saturated porous media, Journal of Nanoparticle Research, 12 (2010) 2371-2380. 
[48] S. Aramrak, M. Flury, J.B. Harsh, R.L. Zollars, H.P. Davis, Does colloid shape affect detachment of colloids by a moving air-water interface?, Langmuir, 29 (2013) 5770-5780.

[49] M.B. Seymour, G. Chen, C. Su, Y. Li, Transport and retention of colloids in porous media: does shape really matter?, Environmental science \& technology, 47 (2013) 8391-8398.

[50] T. Knappenberger, S. Aramrak, M. Flury, Transport of barrel and spherical shaped colloids in unsaturated porous media, J Contam Hydrol, 180 (2015) 69-79.

[51] Q. Liu, V. Lazouskaya, Q. He, Y. Jin, Effect of particle shape on colloid retention and release in saturated porous media, Journal of environmental quality, 39 (2010) 500-508.

[52] S.P. Xu, Q. Liao, J.E. Saiers, Straining of nonspherical colloids in saturated porous media, Environmental science \& technology, 42 (2008) 771-778.

[53] P. Christian, F. Von der Kammer, M. Baalousha, T. Hofmann, Nanoparticles: structure, properties, preparation and behaviour in environmental media, Ecotoxicology, 17 (2008) 326-343.

[54] M. Hedayati, Mobilization and transport of different types of carbon-based engineered and natural nanoparticles through saturated porous media, in, 2014.

[55] D.P. Jaisi, N.B. Saleh, R.E. Blake, M. Elimelech, Transport of Single-Walled Carbon Nanotubes in Porous Media: Filtration Mechanisms and Reversibility, Environmental science \& technology, 42 (2008) 8317-8323. 
[56] D. Kasel, S.A. Bradford, J. Simunek, M. Heggen, H. Vereecken, E. Klumpp, Transport and retention of multi-walled carbon nanotubes in saturated porous media: Effects of input concentration and grain size, Water research, 47 (2013) 933-944.

[57] M. Elimelech, Effect of Particle-Size on the Kinetics of Particle Deposition under Attractive Double-Layer Interactions, Journal of colloid and interface science, 164 (1994) 190-199.

[58] C. Wang, A.D. Bobba, R. Attinti, C. Shen, V. Lazouskaya, L.P. Wang, Y. Jin, Retention and transport of silica nanoparticles in saturated porous media: effect of concentration and particle size, Environmental science \& technology, 46 (2012) 7151-7158.

[59] D.M. O'Carroll, X. Liu, N.T. Mattison, E.J. Petersen, Impact of diameter on carbon nanotube transport in sand, Journal of colloid and interface science, 390 (2013) 96-104.

[60] S. Sasidharan, S. Torkzaban, S.A. Bradford, P.J. Dillon, P.G. Cook, Coupled effects of hydrodynamic and solution chemistry on long-term nanoparticle transport and deposition in saturated porous media, Colloids and Surfaces A: Physicochemical and Engineering Aspects, 457 (2014) 169-179.

[61] Y.S. Li, Y.G. Wang, K.D. Pennell, L.M. Abriola, Investigation of the transport and deposition of fullerene $\left(\mathrm{C}_{60}\right)$ nanoparticles in quartz sands under varying flow conditions, Environmental science \& technology, 42 (2008) 7174-7180.

[62] Y.T. He, J.M. Wan, T. Tokunaga, Kinetic stability of hematite nanoparticles: the effect of particle sizes, Journal of Nanoparticle Research, 10 (2008) 321-332. 
[63] N. Tufenkji, M. Elimelech, Correlation equation for predicting single-collector efficiency in physicochemical filtration in saturated porous media, Environmental science \& technology, 38 (2004) 529-536.

[64] R. May, Y. Li, The effects of particle size on the deposition of fluorescent nanoparticles in porous media: Direct observation using laser scanning cytometry, Colloids and Surfaces A: Physicochemical and Engineering Aspects, 418 (2013) 84-91.

[65] S. Tripathi, D. Champagne, N. Tufenkji, Transport behavior of selected nanoparticles with different surface coatings in granular porous media coated with Pseudomonas aeruginosa biofilm, Environmental science \& technology, 46 (2012) 6942-6949.

[66] Y.G. Wang, J.H. Kim, J.B. Baek, G.W. Miller, K.D. Pennell, Transport behavior of functionalized multi-wall carbon nanotubes in water-saturated quartz sand as a function of tube length, Water research, 46 (2012) 4521-4531.

[67] A.J. Pelley, N. Tufenkji, Effect of particle size and natural organic matter on the migration of nano- and microscale latex particles in saturated porous media, Journal of colloid and interface science, 321 (2008) 74-83.

[68] Y. Wang, B. Gao, V.L. Morales, Y. Tian, L. Wu, J. Gao, W. Bai, L. Yang, Transport of titanium dioxide nanoparticles in saturated porous media under various solution chemistry conditions, J Nanopart Res, 14 (2012) 1095. 
[69] M. Auffan, J. Rose, J.Y. Bottero, G.V. Lowry, J.P. Jolivet, M.R. Wiesner, Towards a definition of inorganic nanoparticles from an environmental, health and safety perspective, Nat Nanotechnol, 4 (2009) 634-641.

[70] T. Phenrat, H.J. Kim, F. Fagerlund, T. Illangasekare, R.D. Tilton, G.V. Lowry, Particle Size Distribution, Concentration, and Magnetic Attraction Affect Transport of Polymer-Modified Fe-0 Nanoparticles in Sand Columns, Environmental science \& technology, 43 (2009) 5079-5085.

[71] R. Behra, B. Wagner, L. Sgier, D. Kistler, Colloidal Stability and Toxicity of Gold Nanoparticles and Gold Chloride on Chlamydomonas reinhardtii, Aquat Geochem, 21 (2015) $331-342$.

[72] M. Farre, K. Gajda-Schrantz, L. Kantiani, D. Barcelo, Ecotoxicity and analysis of nanomaterials in the aquatic environment, Anal Bioanal Chem, 393 (2009) 81-95.

[73] S. Perez, M. Farre, D. Barcelo, Analysis, behavior and ecotoxicity of carbon-based nanomaterials in the aquatic environment, Trac-Trend Anal Chem, 28 (2009) 820-832.

[74] M. Baalousha, M. Sikder, A. Prasad, J. Lead, R. Merrifield, G.T. Chandler, The concentration-dependent behaviour of nanoparticles, Environmental Chemistry, (2015).

[75] K. Loza, J. Diendorf, C. Sengstock, L. Ruiz-Gonzalez, J.M. Gonzalez-Calbet, M. Vallet-Regi, M. Koller, M. Epple, The dissolution and biological effects of silver nanoparticles in biological media, J Mater Chem B, 2 (2014) 1634-1643. 
[76] Y. Lu, X. Xu, K. Yang, D. Lin, The effects of surfactants and solution chemistry on the transport of multiwalled carbon nanotubes in quartz sand-packed columns, Environmental pollution, 182 (2013) 269-277.

[77] T. Rahman, J. George, H.J. Shipley, Transport of aluminum oxide nanoparticles in saturated sand: effects of ionic strength, flow rate, and nanoparticle concentration, The Science of the total environment, 463-464 (2013) 565-571.

[78] T. Rahman, H. Millwater, H.J. Shipley, Modeling and sensitivity analysis on the transport of aluminum oxide nanoparticles in saturated sand: effects of ionic strength, flow rate, and nanoparticle concentration, The Science of the total environment, 499 (2014) 402-412.

[79] Y. Liang, S.A. Bradford, J. Simunek, H. Vereecken, E. Klumpp, Sensitivity of the transport and retention of stabilized silver nanoparticles to physicochemical factors, Water Res, 47 (2013) 2572-2582.

[80] G.R. Aiken, H. Hsu-Kim, J.N. Ryan, Influence of dissolved organic matter on the environmental fate of metals, nanoparticles, and colloids, Environmental science \& technology, 45 (2011) 3196-3201.

[81] F. Loosli, P. Le Coustumer, S. Stoll, TiO2 nanoparticles aggregation and disaggregation in presence of alginate and Suwannee River humic acids. $\mathrm{pH}$ and concentration effects on nanoparticle stability, Water research, 47 (2013) 6052-6063. 
[82] J. Fang, X.Q. Shan, B. Wen, R.X. Huang, Mobility of TX100 suspended multiwalled carbon nanotubes (MWCNTs) and the facilitated transport of phenanthrene in real soil columns, Geoderma, 207 (2013) 1-7.

[83] A.R. Petosa, S.J. Brennan, F. Rajput, N. Tufenkji, Transport of two metal oxide nanoparticles in saturated granular porous media: Role of water chemistry and particle coating, Water Res, 46 (2012) 1273-1285.

[84] I.G. Godinez, C.J. Darnault, A.P. Khodadoust, D. Bogdan, Deposition and release kinetics of nano-TiO2 in saturated porous media: effects of solution ionic strength and surfactants, Environmental pollution, 174 (2013) 106-113.

[85] P.D. Sun, K.K. Zhang, J. Fang, D.H. Lin, M.H. Wang, J.Y. Han, Transport of TiO2 nanoparticles in soil in the presence of surfactants, Science of the Total Environment, 527 (2015) $420-428$.

[86] W. Fan, X.H. Jiang, Y. Lu, M.X. Huo, S.S. Lin, Z. Geng, Effects of surfactants on graphene oxide nanoparticles transport in saturated porous media, J Environ Sci-China, 35 (2015) 12-19.

[87] D. Bouchard, W. Zhang, T. Powell, U.S. Rattanaudompol, Aggregation Kinetics and Transport of Single-Walled Carbon Nanotubes at Low Surfactant Concentrations, Environmental science \& technology, 46 (2012) 4458-4465. 
[88] Y. Lu, K. Yang, D. Lin, Transport of surfactant-facilitated multiwalled carbon nanotube suspensions in columns packed with sized soil particles, Environmental pollution, 192 (2014) $36-43$.

[89] L. Liu, B. Gao, L. Wu, Y.Y. Sun, Z.H. Zhou, Effects of surfactant type and concentration on graphene retention and transport in saturated porous media, Chem Eng J, 262 (2015) 1187-1191.

[90] D. Wang, C. Su, C. Liu, D. Zhou, Transport of fluorescently labeled hydroxyapatite nanoparticles in saturated granular media at environmentally relevant concentrations of surfactants, Colloid Surface A, 457 (2014) 58-66.

[91] T. Ben-Moshe, I. Dror, B. Berkowitz, Transport of metal oxide nanoparticles in saturated porous media, Chemosphere, 81 (2010) 387-393.

[92] S. Ghosh, H. Mashayekhi, P. Bhowmik, B.S. Xing, Colloidal Stability of Al2O3 Nanoparticles as Affected by Coating of Structurally Different Humic Acids, Langmuir, 26 (2010) 873-879.

[93] J.D. Hu, Y. Zevi, X.M. Kou, J. Xiao, X.J. Wang, Y. Jin, Effect of dissolved organic matter on the stability of magnetite nanoparticles under different $\mathrm{pH}$ and ionic strength conditions, Science of the Total Environment, 408 (2010) 3477-3489.

[94] I.A. Mudunkotuwa, J.M. Pettibone, V.H. Grassian, Environmental implications of nanoparticle aging in the processing and fate of copper-based nanomaterials, Environmental science \& technology, 46 (2012) 7001-7010. 
[95] Y. Tian, B. Gao, V.L. Morales, Y. Wang, L. Wu, Effect of surface modification on single-walled carbon nanotube retention and transport in saturated and unsaturated porous media, J Hazard Mater, 239 (2012) 333-339.

[96] L. Liu, B. Gao, L. Wu, V.L. Morales, L.Y. Yang, Z.H. Zhou, H. Wang, Deposition and transport of graphene oxide in saturated and unsaturated porous media, Chem Eng J, 229 (2013) 444-449.

[97] V.L. Morales, W. Zhang, B. Gao, L.W. Lion, J.J. Bisogni, B.A. McDonough, T.S. Steenhuis, Impact of dissolved organic matter on colloid transport in the vadose zone: Deterministic approximation of transport deposition coefficients from polymeric coating characteristics, Water Res, 45 (2011) 1691-1701.

[98] L. Wu, B. Gao, Y. Tian, R. Munoz-Carpena, K.J. Zigler, DLVO interactions of carbon nanotubes with isotropic planar surfaces, Langmuir, 29 (2013) 3976-3988.

[99] D. Grasso, K. Subramaniam, M. Butkus, K. Strevett, J. Bergendahl, A review of non-DLVO interactions in environmental colloidal systems, Reviews in Environmental Science and Biotechnology, 1 (2002) 17-38.

[100] G. Yang, H. Tu, C. Hung, Stability of nanoiron slurries and their transport in the subsurface environment, Separation and Purification Technology, 58 (2007) 166-172.

[101] Y.G. Wang, Y.S. Li, J.D. Fortner, J.B. Hughes, L.M. Abriola, K.D. Pennell, Transport and retention of nanoscale C-60 aggregates in water-saturated porous media, Environmental science \& technology, 42 (2008) 3588-3594. 
[102] S.R. Kanel, D. Nepal, B. Manning, H. Choi, Transport of surface-modified iron nanoparticle in porous media and application to arsenic(III) remediation, Journal of Nanoparticle Research, 9 (2007) 725-735.

[103] J. Fang, X.Q. Shan, B. Wen, J.M. Lin, G. Owens, Stability of titania nanoparticles in soil suspensions and transport in saturated homogeneous soil columns, Environmental pollution, 157 (2009) 1101-1109.

[104] A.R. Petosa, C. Ohl, F. Rajput, N. Tufenkji, Mobility of nanosized cerium dioxide and polymeric capsules in quartz and loamy sands saturated with model and natural groundwaters, Water research, 47 (2013) 5889-5900.

[105] Z.T. Han, F.W. Zhang, D.H. Lin, B.S. Xing, Clay minerals affect the stability of surfactant-facilitated carbon nanotube suspensions, Environmental science \& technology, 42 (2008) 6869-6875.

[106] O. Sagee, I. Dror, B. Berkowitz, Transport of silver nanoparticles (AgNPs) in soil, Chemosphere, 88 (2012) 670-675.

[107] A. Braun, E. Klumpp, R. Azzam, C. Neukum, Transport and deposition of stabilized engineered silver nanoparticles in water saturated loamy sand and silty loam, The Science of the total environment, 535 (2015) 102-112.

[108] P. Han, X. Wang, L. Cai, M. Tong, H. Kim, Transport and retention behaviors of titanium dioxide nanoparticles in iron oxide-coated quartz sand: Effects of $\mathrm{pH}$, ionic strength, 
and humic acid, Colloids and Surfaces A: Physicochemical and Engineering Aspects, 454 (2014) 119-127.

[109] L. Chen, D.A. Sabatini, T.C. Kibbey, Transport and retention of fullerene $\left(\mathrm{nC}_{60}\right)$ nanoparticles in unsaturated porous media: effects of solution chemistry and solid phase coating, Journal of contaminant hydrology, 138-139 (2012) 104-112.

[110] K. Shellenberger, B.E. Logan, Effect of molecular scale roughness of glass beads on colloidal and bacterial deposition, Environmental science \& technology, 36 (2002) 184-189.

[111] C.Y. Shen, B.G. Li, C. Wang, Y.F. Huang, Y. Jin, Surface Roughness Effect on Deposition of Nano- and Micro-Sized Colloids in Saturated Columns at Different Solution Ionic Strengths, Vadose Zone J, 10 (2011) 1071-1081.

[112] V.L. Morales, B. Gao, T.S. Steenhuis, Grain surface-roughness effects on colloidal retention in the vadose zone, Vadose Zone J, 8 (2009) 11-20.

[113] B. Gao, T.S. Steenhuis, Y. Zevi, V.L. Morales, J.L. Nieber, B.K. Richards, J.F. McCarthy, J.Y. Parlange, Capillary retention of colloids in unsaturated porous media, Water Resour Res, 44 (2008) 7.

[114] N.T. Mattison, D.M. O'Carroll, R.K. Rowe, E.J. Petersen, Impact of Porous Media Grain Size on the Transport of Multi-walled Carbon Nanotubes, Environmental science \& technology, 45 (2011) 9765-9775. 
[115] P. Sharma, D. Bao, F. Fagerlund, Deposition and mobilization of functionalized multiwall carbon nanotubes in saturated porous media: effect of grain size, flow velocity and solution chemistry, Environmental Earth Sciences, 72 (2014) 3025-3035.

[116] J. Xin, F. Tang, X. Zheng, H. Shao, O. Kolditz, Transport and retention of xanthan gum-stabilized microscale zero-valent iron particles in saturated porous media, Water research, 88 (2015) 199-206.

[117] A. Mekonen, P. Sharma, F. Fagerlund, Transport and mobilization of multiwall carbon nanotubes in quartz sand under varying saturation, Environmental Earth Sciences, 71 (2013) $3751-3760$.

[118] T. Phenrat, H.J. Kim, F. Fagerlund, T. Illangasekare, G.V. Lowry, Empirical correlations to estimate agglomerate size and deposition during injection of a polyelectrolyte-modified $\mathrm{Fe} 0$ nanoparticle at high particle concentration in saturated sand, Journal of contaminant hydrology, 118 (2010) 152-164.

[119] S. Torkzaban, S.A. Bradford, S.L. Walker, Resolving the coupled effects of hydrodynamics and DLVO forces on colloid attachment in porous media, Langmuir, 23 (2007) 9652-9660.

[120] W.P. Johnson, M.P. Tong, Observed and simulated fluid drag effects on colloid deposition in the presence of an energy barrier in an impinging jet system, Environmental science \& technology, 40 (2006) 5015-5021. 
[121] S.A. Bradford, J. Simunek, M. Bettahar, M.T. Van Genuchten, S.R. Yates, Modeling colloid attachment, straining, and exclusion in saturated porous media, Environmental science \& technology, 37 (2003) 2242-2250.

[122] L. Chen, D.A. Sabatini, T.C. Kibbey, Retention and release of TiO2 nanoparticles in unsaturated porous media during dynamic saturation change, Journal of contaminant hydrology, 118 (2010) 199-207.

[123] Y. Zevi, A. Dathe, B. Gao, W. Zhang, B.K. Richards, T.S. Steenhuis, Transport and retention of colloidal particles in partially saturated porous media: Effect of ionic strength, Water Resour Res, 45 (2009) W12403.

[124] Y. Zevi, B. Gao, W. Zhang, V.L. Morales, M.E. Cakmak, E.A. Medrano, W.J. Sang, T.S. Steenhuis, Colloid retention at the meniscus-wall contact line in an open microchannel, Water Res, 46 (2012) 295-306.

[125] L. Liu, B. Gao, L. Wu, V.L. Morales, L. Yang, Z. Zhou, H. Wang, Deposition and transport of graphene oxide in saturated and unsaturated porous media, Chem Eng J, 229 (2013) 444-449.

[126] W. Zhang, C.W. Isaacson, U.S. Rattanaudompol, T.B. Powell, D. Bouchard, Fullerene nanoparticles exhibit greater retention in freshwater sediment than in model porous media, Water research, 46 (2012) 2992-3004. 
[127] L.X. Chen, D.A. Sabatini, T.C.G. Kibbey, Role of the air-water interface in the retention of $\mathrm{TiO}_{2}$ nanoparticles in porous media during primary drainage, Environ Sci Technol, 42 (2008) 1916-1921.

[128] J. Fang, M.J. Xu, D.J. Wang, B. Wen, J.Y. Han, Modeling the transport of TiO2 nanoparticle aggregates in saturated and unsaturated granular media: effects of ionic strength and pH, Water research, 47 (2013) 1399-1408.

[129] S.A. Bradford, S. Torkzaban, J. Simunek, Modeling colloid transport and retention in saturated porous media under unfavorable attachment conditions, Water Resour Res, 47 (2011).

[130] K.M. Yao, M.M. Habibian, C.R. Omelia, Water and Waste Water Filtration - Concepts and Applications, Environmental science \& technology, 5 (1971) 1105-\&.

[131] A. Taghavy, A. Mittelman, Y.G. Wang, K.D. Pennell, L.M. Abriola, Mathematical Modeling of the Transport and Dissolution of Citrate-Stabilized Silver Nanoparticles in Porous Media, Environmental science \& technology, 47 (2013) 8499-8507.

[132] B. Gao, J.E. Saiers, J. Ryan, Pore-scale mechanisms of colloid deposition and mobilization during steady and transient flow through unsaturated granular media, Water Resour Res, 42 (2006) W01410.

[133] H.F. Lecoanet, M.R. Wiesner, Velocity effects on fullerene and oxide nanoparticle deposition in porous media, Environmental science \& technology, 38 (2004) 4377-4382. 
[134] J.D. Lanphere, C.J. Luth, L.M. Guiney, N.D. Mansukhani, M.C. Hersam, S.L. Walker, Fate and Transport of Molybdenum Disulfide Nanomaterials in Sand Columns, Environmental engineering science, 32 (2015) 163-173.

[135] K.A.D. Guzman, M.P. Finnegan, J.F. Banfield, Influence of surface potential on aggregation and transport of titania nanoparticles, Environmental science \& technology, 40 (2006) 7688-7693.

[136] I.G. Godinez, C.J.G. Darnault, Aggregation and transport of nano-TiO2 in saturated porous media: Effects of pH, surfactants and flow velocity, Water research, 45 (2011) 839-851.

[137] S.K. Kumahor, P. Hron, G. Metreveli, G.E. Schaumann, H.J. Vogel, Transport of citrate-coated silver nanoparticles in unsaturated sand, Science of the Total Environment, 535 (2015) 113-121.

[138] T. Tosco, J. Bosch, R.U. Meckenstock, R. Sethi, Transport of Ferrihydrite Nanoparticles in Saturated Porous Media: Role of Ionic Strength and Flow Rate, Environmental science \& technology, 46 (2012) 4008-4015.

[139] I. Chowdhury, N.D. Mansukhani, L.M. Guiney, M.C. Hersam, D. Bouchard, Aggregation and Stability of Reduced Graphene Oxide: Complex Roles of Divalent Cations, pH, and Natural Organic Matter, Environmental science \& technology, 49 (2015) 10886-10893.

[140] L. Feriancikova, S.P. Xu, Deposition and remobilization of graphene oxide within saturated sand packs, Journal of hazardous materials, 235 (2012) 194-200. 
[141] J. Brant, H. Lecoanet, M.R. Wiesner, Aggregation and deposition characteristics of fullerene nanoparticles in aqueous systems, Journal of Nanoparticle Research, 7 (2005) 545-553.

[142] I. Chowdhury, M.C. Duch, N.D. Mansukhani, M.C. Hersam, D. Bouchard, Deposition and Release of Graphene Oxide Nanomaterials Using a Quartz Crystal Microbalance, Environmental science \& technology, 48 (2014) 961-969.

[143] M.W. Hahn, C.R. O'Melia, Deposition and reentrainment of Brownian particles in porous media under unfavorable chemical conditions: Some concepts and applications, Environ Sci Technol, 38 (2004) 210-220.

[144] T. Mengestab, Fate and Transport of Nano-TiO2 in Saturated Porous Media: Effect of pH, Ionic Strength and Flow Rate, in: Department of Earth Sciences, Uppsala University, 2015, pp. 24.

[145] L. Wu, L. Liu, B. Gao, R. Munoz-Carpena, M. Zhang, H. Chen, Z.H. Zhou, H. Wang, Aggregation Kinetics of Graphene Oxides in Aqueous Solutions: Experiments, Mechanisms, and Modeling, Langmuir, 29 (2013) 15174-15181.

[146] T.H. Nguyen, K.L. Chen, Role of divalent cations in plasmid DNA adsorption to natural organic matter-coated silica surface, Environmental science \& technology, 41 (2007) $5370-5375$.

[147] T.R. Fadel, T.M. Fahmy, Immunotherapy applications of carbon nanotubes: from design to safe applications, Trends Biotechnol, 32 (2014) 198-209. 
[148] M.C. Serrano, M.C. Gutierrez, F. del Monte, Role of polymers in the design of 3D carbon nanotube-based scaffolds for biomedical applications, Prog Polym Sci, 39 (2014) $1448-1471$.

[149] M.T. Byrne, Y.K. Gun'ko, Recent Advances in Research on Carbon Nanotube-Polymer Composites, Adv Mater, 22 (2010) 1672-1688.

[150] S. Goenka, V. Sant, S. Sant, Graphene-based nanomaterials for drug delivery and tissue engineering, J Control Release, 173 (2014) 75-88.

[151] M.B. Xing, R.X. Wang, J.L. Yu, Application of fullerene C-60 nano-oil for performance enhancement of domestic refrigerator compressors, Int J Refrig, 40 (2014) 398-403.

[152] S. Banya, T. Akiyama, T. Matsumoto, K. Fujita, T. Oku, Facile Fabrication and Photovoltaic Application of [60]Fullerene Assembly Films Formed by Reaction between Fullerene and Amines, B Chem Soc Jpn, 87 (2014) 1335-1342.

[153] X.B. Chen, A. Selloni, Introduction: Titanium Dioxide (TiO2) Nanomaterials, Chem Rev, 114 (2014) 9281-9282.

[154] Y. Bai, I. Mora-Sero, F. De Angelis, J. Bisquert, P. Wang, Titanium Dioxide Nanomaterials for Photovoltaic Applications, Chem Rev, 114 (2014) 10095-10130.

[155] C. Mondal, A.K. Sinha, M. Ganguly, J. Pal, S. Dhara, Y. Negishi, T. Pal, Deposition of zinc oxide nanomaterial on different substrates for useful applications, Crystengcomm, 16 (2014) $4322-4328$. 
[156] L. Mu, R.L. Sprando, Application of Nanotechnology in Cosmetics, Pharm Res-Dordr, 27 (2010) 1746-1749.

[157] M.D. Newman, M. Stotland, J.I. Ellis, The safety of nanosized particles in titanium dioxide- and zinc oxide-based sunscreens, J Am Acad Dermatol, 61 (2009) 685-692.

[158] J. Kim, K. Yong, Mechanism Study of ZnO Nanorod-Bundle Sensors for H2S Gas Sensing, J Phys Chem C, 115 (2011) 7218-7224.

[159] T.M. Benn, P. Westerhoff, Nanoparticle silver released into water from commercially available sock fabrics, Environmental science \& technology, 42 (2008) 4133-4139.

[160] V. Amendola, S. Polizzi, M. Meneghetti, Free silver nanoparticles synthesized by laser ablation in organic solvents and their easy functionalization, Langmuir, 23 (2007) $6766-6770$.

[161] N. Duran, P.D. Marcato, G.I.H. De Souza, O.L. Alves, E. Esposito, Antibacterial effect of silver nanoparticles produced by fungal process on textile fabrics and their effluent treatment, J Biomed Nanotechnol, 3 (2007) 203-208.

[162] A. Panacek, L. Kvitek, R. Prucek, M. Kolar, R. Vecerova, N. Pizurova, V.K. Sharma, T. Nevecna, R. Zboril, Silver colloid nanoparticles: Synthesis, characterization, and their antibacterial activity, J Phys Chem B, 110 (2006) 16248-16253.

[163] C. Baker, A. Pradhan, L. Pakstis, D.J. Pochan, S.I. Shah, Synthesis and antibacterial properties of silver nanoparticles, J Nanosci Nanotechno, 5 (2005) 244-249. 
[164] R. Kaegi, B. Sinnet, S. Zuleeg, H. Hagendorfer, E. Mueller, R. Vonbank, M. Boller, M. Burkhardt, Release of silver nanoparticles from outdoor facades, Environmental pollution, 158 (2010) 2900-2905.

[165] C. Larue, H. Castillo-Michel, S. Sobanska, L. Cecillon, S. Bureau, V. Barthes, L. Ouerdane, M. Carriere, G. Sarret, Foliar exposure of the crop Lactuca sativa to silver nanoparticles: Evidence for internalization and changes in Ag speciation, Journal of hazardous materials, 264 (2014) 98-106.

[166] W.J. Cui, W.S. Lu, Y.K. Zhang, G.H. Lin, T.X. Wei, L. Jiang, Gold nanoparticle ink suitable for electric-conductive pattern fabrication using in ink-jet printing technology, Colloid Surface A, 358 (2010) 35-41.

[167] M.M. Deng, X.Y. Zhang, Z.L. Zhang, Z.Q. Xin, Y.L. Song, A Gold Nanoparticle Ink Suitable for the Fabrication of Electrochemical Electrode by Inkjet Printing, J Nanosci Nanotechno, 14 (2014) 5114-5119.

[168] A. Majdalawieh, M.C. Kanan, O. El-Kadri, S.M. Kanan, Recent Advances in Gold and Silver Nanoparticles: Synthesis and Applications, J Nanosci Nanotechno, 14 (2014) 4757-4780.

[169] A.M. Mohammed, R.A. Rahim, I.J. Ibraheem, F.K. Loong, H. Hisham, U. Hashim, Y. Al-Douri, Application of Gold Nanoparticles for Electrochemical DNA Biosensor, J Nanomater, (2014). 
[170] K.D. Grieger, A. Fjordboge, N.B. Hartmann, E. Eriksson, P.L. Bjerg, A. Baun, Environmental benefits and risks of zero-valent iron nanoparticles (nZVI) for in situ remediation: Risk mitigation or trade-off?, Journal of contaminant hydrology, 118 (2010) 165-183.

[171] A. Maleki, R. Rahimi, S. Maleki, N. Hamidi, Synthesis and characterization of magnetic bromochromate hybrid nanomaterials with triphenylphosphine surface-modified iron oxide nanoparticles and their catalytic application in multicomponent reactions, Rsc Adv, 4 (2014) 29765-29771.

[172] P.A. Xu, G.M. Zeng, D.L. Huang, C.L. Feng, S. Hu, M.H. Zhao, C. Lai, Z. Wei, C. Huang, G.X. Xie, Z.F. Liu, Use of iron oxide nanomaterials in wastewater treatment: A review, Science of the Total Environment, 424 (2012) 1-10.

[173] A. Ananth, S. Dharaneedharan, M.S. Heo, Y.S. Mok, Copper oxide nanomaterials: Synthesis, characterization and structure-specific antibacterial performance, Chem Eng J, 262 (2015) 179-188.

[174] W. Feng, W. Nie, Y.H. Cheng, X.J. Zhou, L. Chen, K.X. Qiu, Z.G. Chen, M.F. Zhu, C.L. He, In vitro and in vivo toxicity studies of copper sulfide nanoplates for potential photothermal applications, Nanomed-Nanotechnol, 11 (2015) 901-912.

[175] S. Goel, F. Chen, W.B. Cai, Synthesis and Biomedical Applications of Copper Sulfide Nanoparticles: From Sensors to Theranostics, Small, 10 (2014) 631-645. 
[176] S. Torkzaban, S.A. Bradford, M.T. van Genuchten, S.L. Walker, Colloid transport in unsaturated porous media: The role of water content and ionic strength on particle straining, $\mathrm{J}$ Contam Hydrol, 96 (2008) 113-127. 
Table 1. Common engineered nanoparticles (ENPs) in the environment

\begin{tabular}{|c|c|c|}
\hline ENPs & Applications/Sources & Reference \\
\hline $\begin{array}{l}\text { CNT } \quad(\text { SWCNT } \\
\& \text { MWCNT })\end{array}$ & $\begin{array}{l}\text { vaccine, scaffolds, biosensors, flexible electrodes in } \\
\text { displays, electronic paper, antistatic coatings, } \\
\text { bullet-proof vests, protective clothing, and } \\
\text { high-performance composites for aircraft and automotive } \\
\text { industries }\end{array}$ & [147-149] \\
\hline $\begin{array}{l}\text { Graphene-based } \\
\text { (graphene, GO, } \\
\text { \& rGO) }\end{array}$ & scaffolds, grafts, biosensors, and drug delivery vehicles & {$[150]$} \\
\hline Fullerene & lubricant additive, solar cells, and semiconductors & {$[151,152]$} \\
\hline $\mathrm{TiO}_{2}$ & $\begin{array}{l}\text { pigment in paints, glazes, enamels, plastics, paper, fibers, } \\
\text { foods, pharmaceuticals, cosmetics, sunscreens, } \\
\text { toothpastes, photocatalytic degradation, and solar cells }\end{array}$ & {$[36,153,154]$} \\
\hline $\mathrm{ZnO}$ & $\begin{array}{l}\text { sunscreens, cosmetics, wide bandgap semiconductor, } \\
\text { UV-light-emitting diodes (LEDs), lasers, solar cells, } \\
\text { field-emission displays, and gas sensors }\end{array}$ & {$[155-158]$} \\
\hline $\mathrm{Ag}$ & $\begin{array}{l}\text { catalyst, biosensors, food containers, paints, printer } \\
\text { inks ,textiles, and antibacterial detergents }\end{array}$ & {$[159-165]$} \\
\hline $\mathrm{Au}$ & printer inks, catalyst, and biosensors & {$[166-169]$} \\
\hline $\begin{array}{l}\text { Fe-based (NZVI, } \\
\left.\mathrm{Fe}_{2} \mathrm{O}_{3}, \& \mathrm{Fe}_{3} \mathrm{O}_{4}\right)\end{array}$ & $\begin{array}{l}\text { environmental remediation, water purification, and } \\
\text { catalyst }\end{array}$ & {$[170-172]$} \\
\hline $\begin{array}{l}\mathrm{Cu} \text {-based }(\mathrm{CuO} \\
\left.\mathrm{Cu}_{2} \mathrm{O}, \& \mathrm{CuS}\right)\end{array}$ & catalyst, sensors, and photothermal agent & {$[173-175]$} \\
\hline
\end{tabular}




\section{Figure Captions}

Fig. 1. Schematic description of environmentalfate and transport of $\operatorname{ENPs}(1$. exchange between atmosphere and ground; 2. atmospheric transport; 3 . fate and transport in the vadose zone; 4.aggregation, transport and transformation in soils; 5. enrichment byterrestrial organisms; 6. aggregation, transport and transformation in groundwater; 7. fate and transport in surface runoff; 8. exchange between surface water and groundwater; 9. fate and transport in subsurface runoff; 10. exchangebetween sediments and water columns; 11. aggregation, transport, and transformation in water; 12. enrichment byaquatic organisms; and 13. accumulation and transfer in food chains).

Fig. 2. Results of a Web of Science search (February 2016)on the topic of ENP transport in porous media.

Fig. 3. Typical carbon-based ENPs.

Fig. 4. Surfactants promoteENP stability.

Fig. 5.ENP transport in unsaturated porous media[176].

Fig. 6. Solution $\mathrm{pH}$ affects ENP surface charge.

Fig. 7.Solution ionic strength affects electric double layer and surface potential of ENPs.

Abscissa (x) and ordinate $(\varphi)$ represent distance and surface potential respectively; $\varphi_{0}$ denotes the potential between nanoparticle core and solution; $\zeta$ and $\zeta^{\prime}$ denote the surface potentials before and after increasing the ionic strength and $\left.\zeta^{\prime}<\zeta\right)$. 
Fig. 1

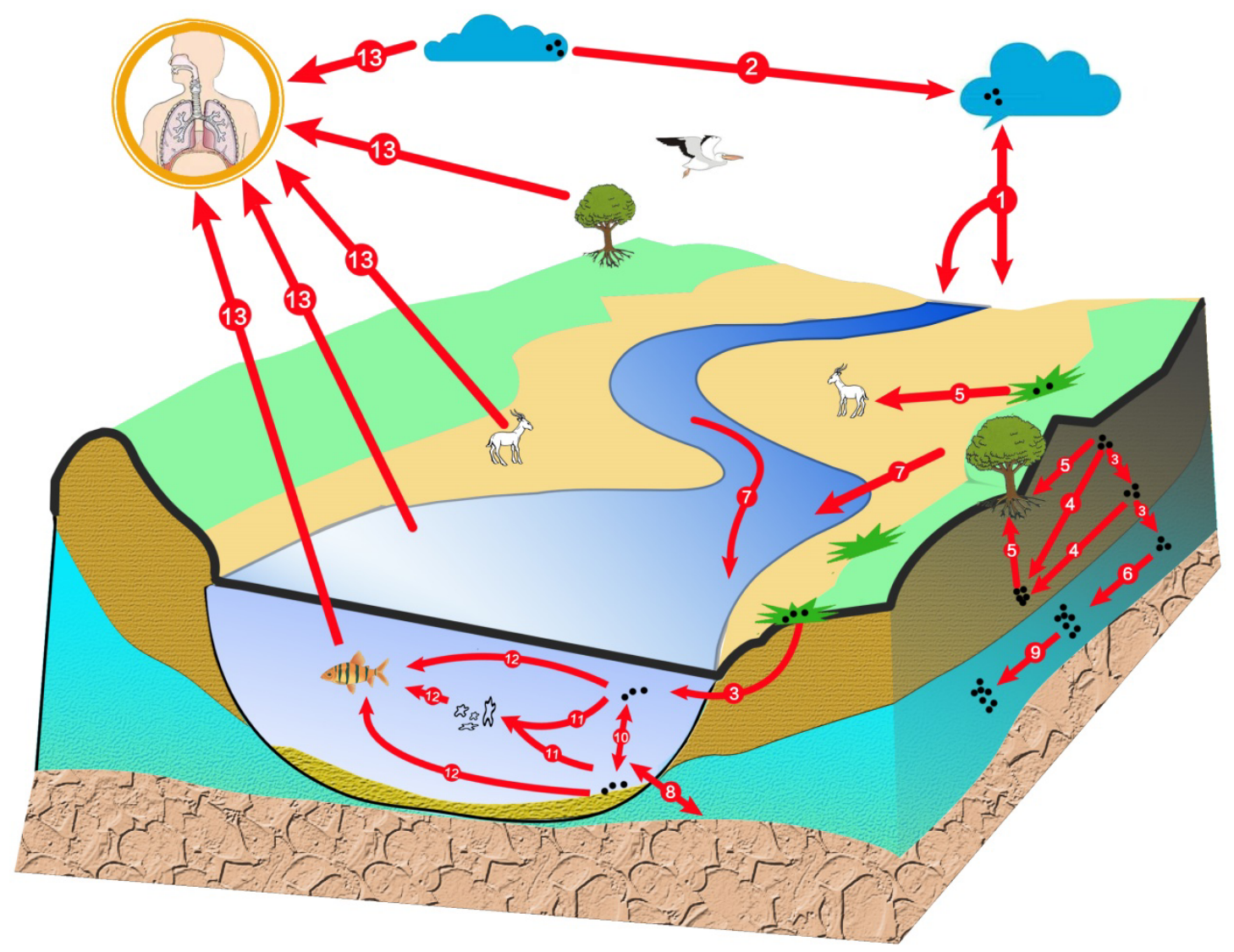


Fig. 2

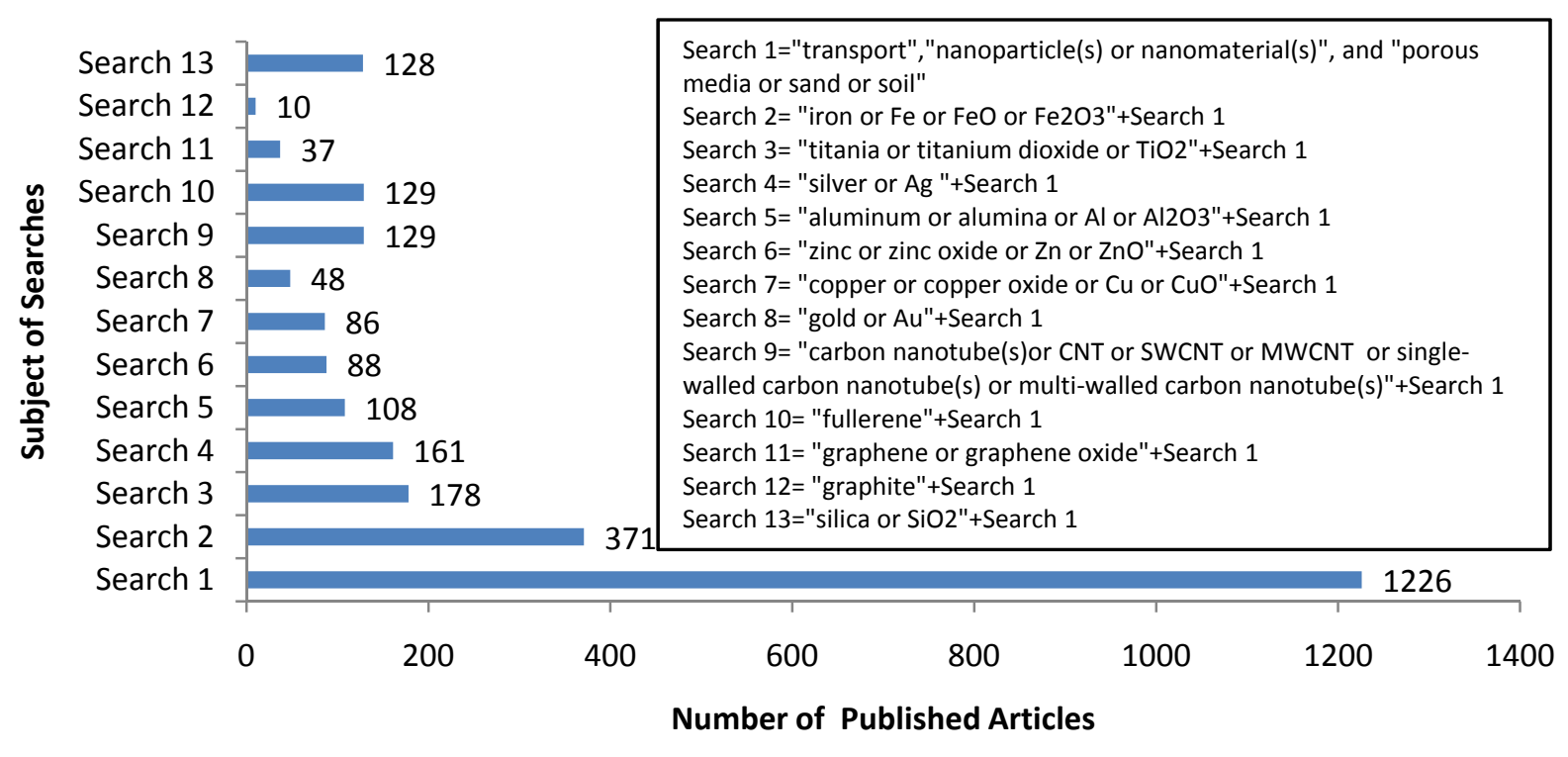

Fig. 3

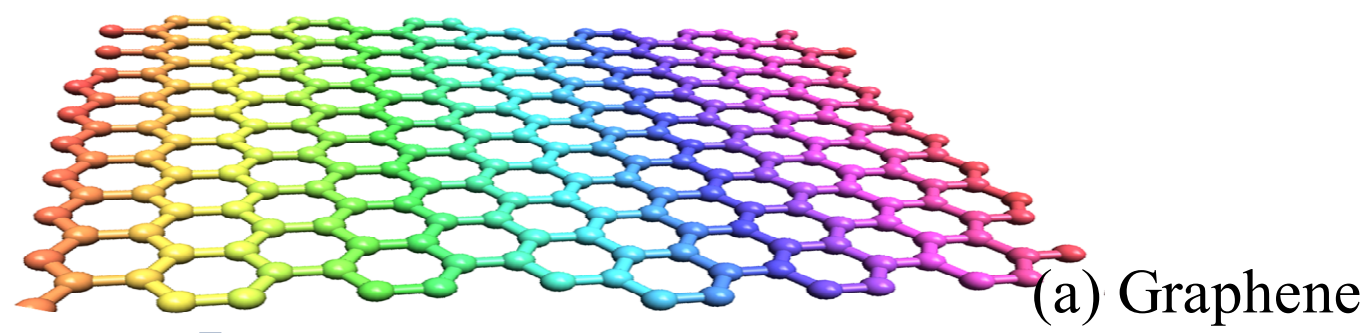

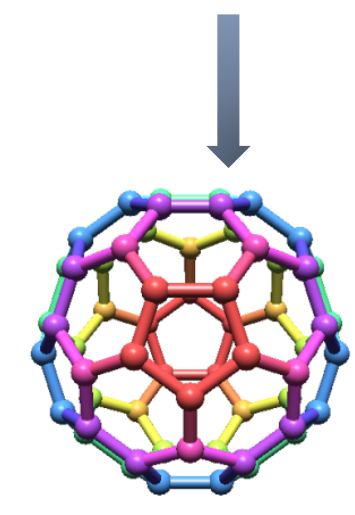

(b) $\mathrm{C} 60$

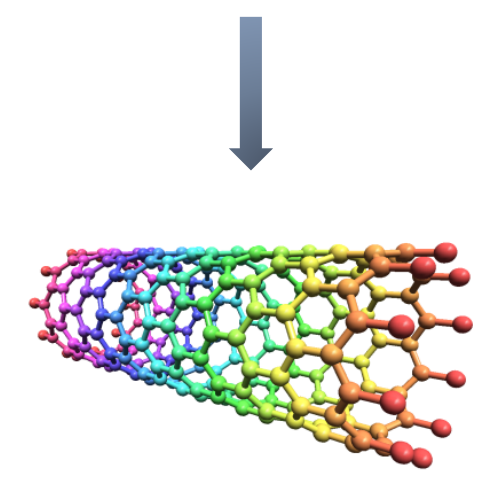

(c) SWCNT

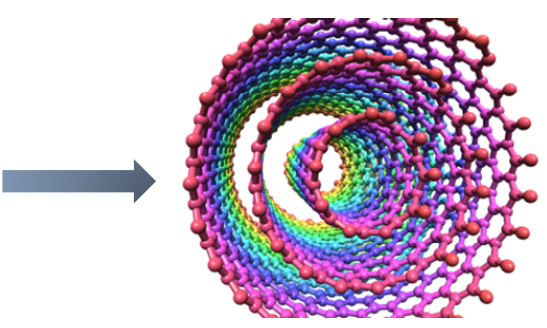

(d) MWCNT 
Fig. 4

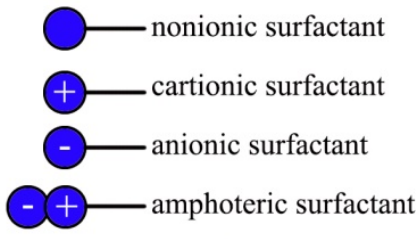

(a) Types of surfacatants ( $\bigcirc$ and $\longrightarrow$ denote hydrophobic group and hydrophilic group respectively)

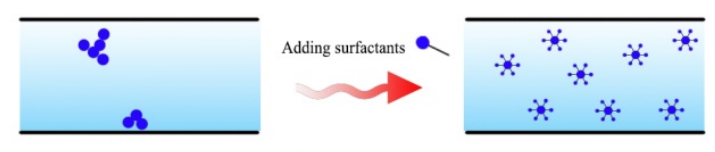

- original NP

$\Varangle$ surfactant-modified NP

(b) Stabilizing effect of surfactants (taking nonionic surfactants as example)

Fig. 5

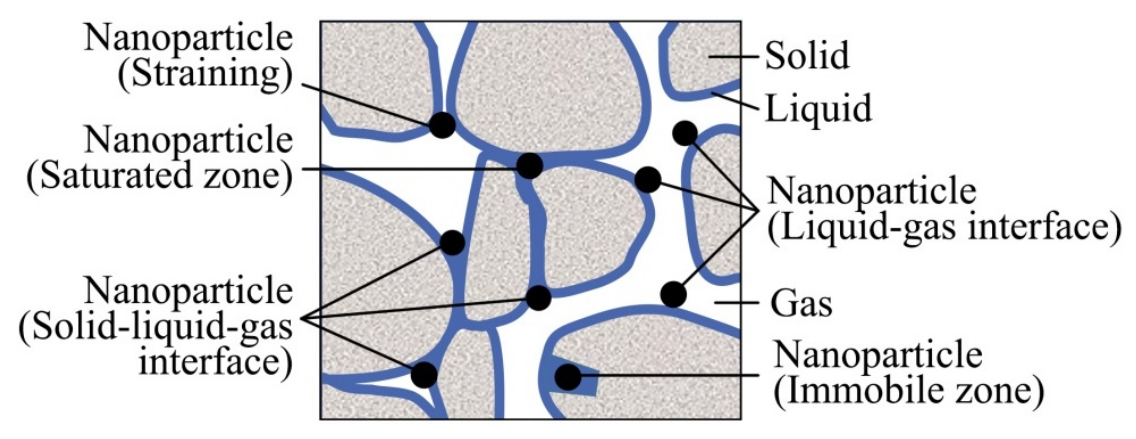

Fig. 6

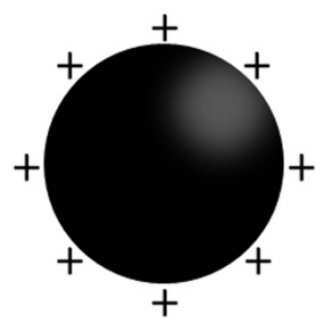

$\mathrm{pH}<\mathrm{pH}_{\mathrm{PZC}}$

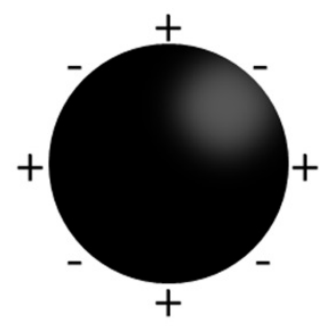

$\mathrm{pH}=\mathrm{pH}_{\mathrm{pZC}}$

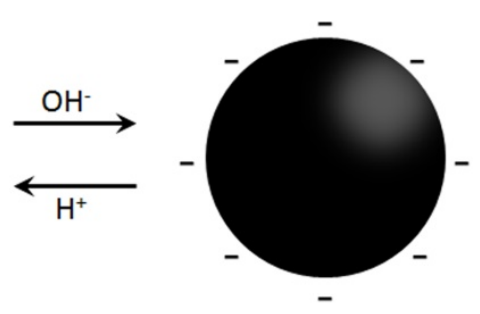

$\mathrm{pH}>\mathrm{pH}_{\mathrm{pZC}}$ 
Fig. 7

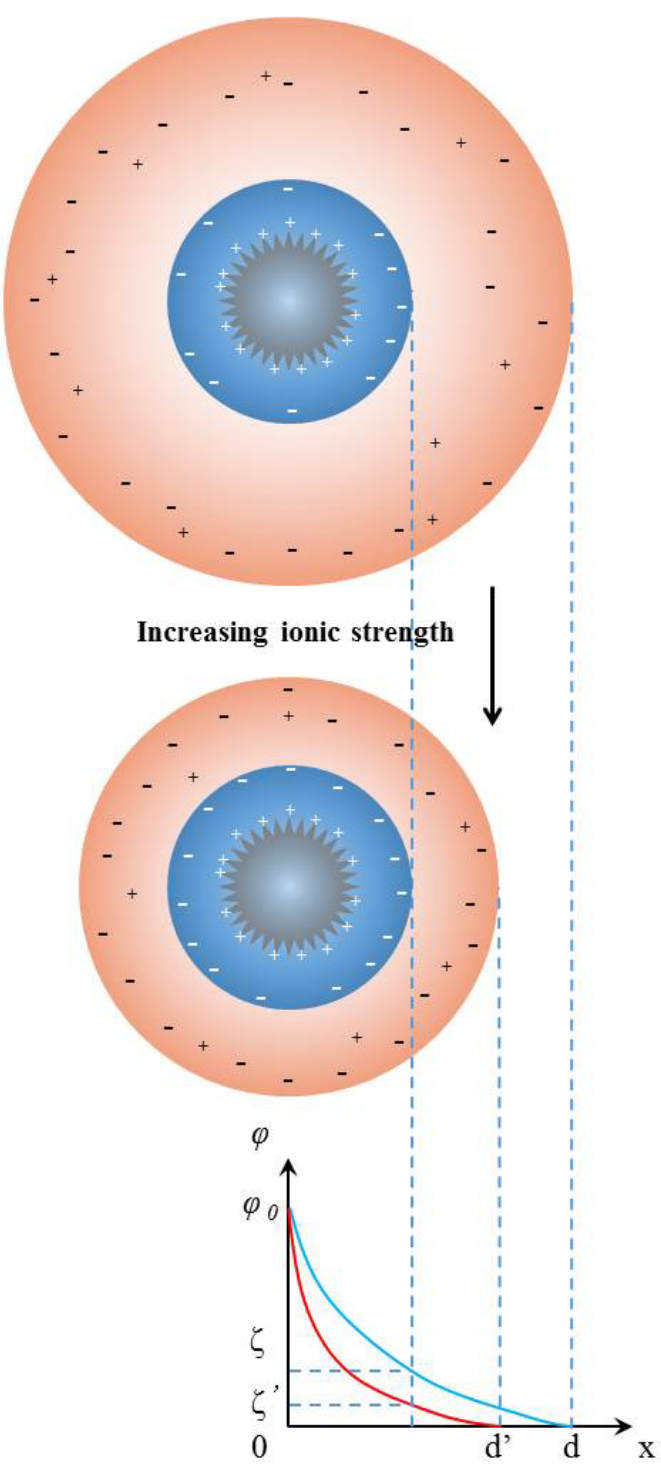




\section{Graphic Abstract}

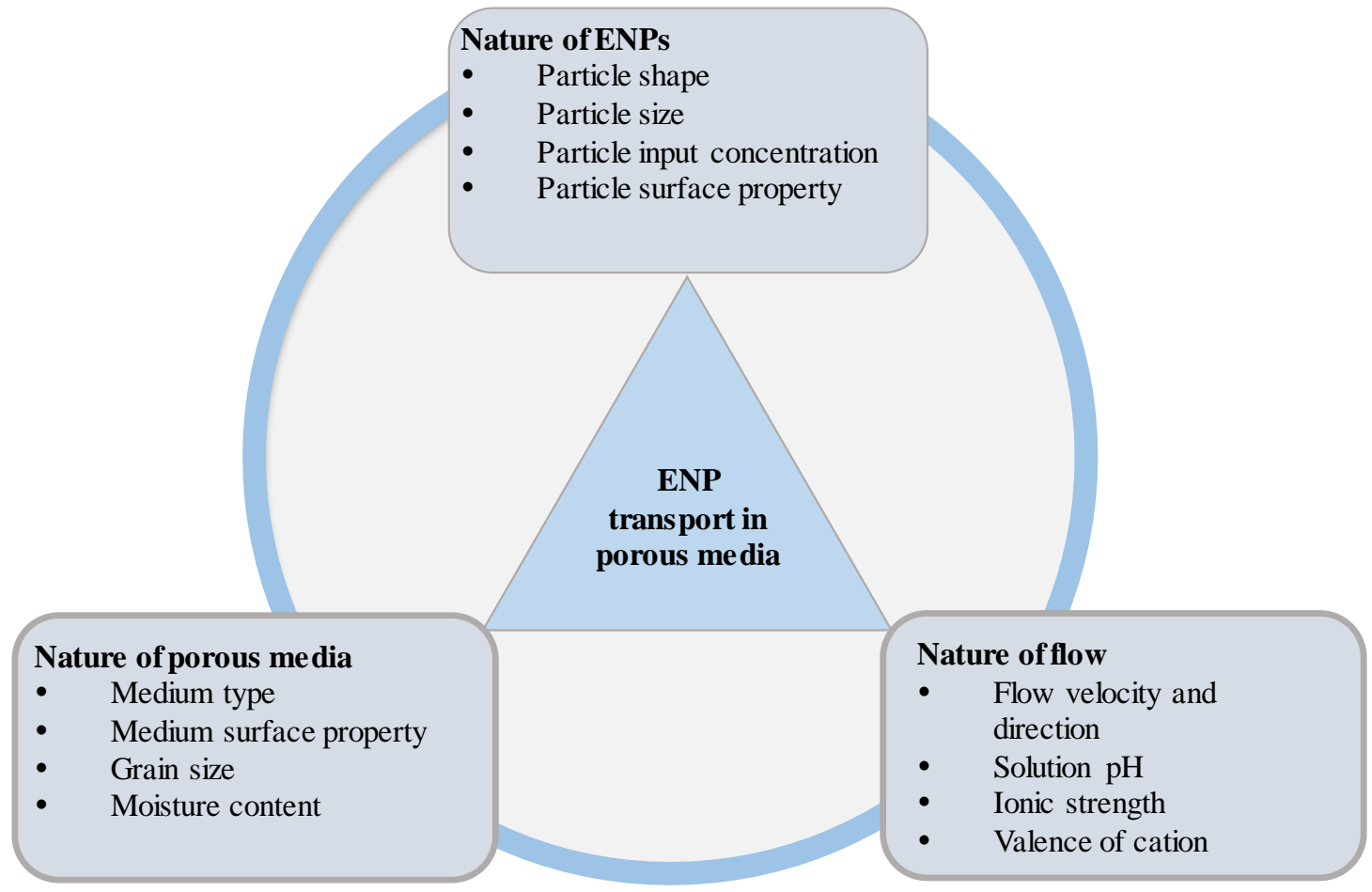

